\title{
Ethnologies
}

\section{Le cinéma de Sembène Ousmane, une (double) contre-ethnographie (Notes pour une recherche)}

\section{Jean Jonassaint}

Volume 31, numéro 2, 2010

Figures noires

Black Images

URI : https://id.erudit.org/iderudit/039372ar

DOI : https://doi.org/10.7202/039372ar

Aller au sommaire du numéro

\section{Éditeur(s)}

Association Canadienne d'Ethnologie et de Folklore

ISSN

1481-5974 (imprimé)

1708-0401 (numérique)

Découvrir la revue

Citer cet article

Jonassaint, J. (2010). Le cinéma de Sembène Ousmane, une (double)

contre-ethnographie : (Notes pour une recherche). Ethnologies, 31(2), 241-286.

https://doi.org/10.7202/039372ar

\section{Résumé de l'article}

Dans un premier temps, cet article brosse brièvement une biographie intellectuelle de Sembène Ousmane pour faire ressortir les rapports entre sa production et sa trajectoire de sujet sénégalais, Ousmane Sembène de son vrai nom, devenu le romancier et cinéaste Sembène Ousmane. Du même coup, à partir d'une lecture de l'évolution des titres de ses romans du français au wolof, du Docker noir (1956) à Xala (1973), il tente d'expliquer son passage de l'écrit à l'écran. Dans un deuxième temps, ce texte montre la cohérence interne de l'oeuvre cinématographique de La Noire de... (1966) à Moolaadé (2004), en passant par Mandabi (1968), Ceddo (1976) ou Camp de Thiaroye (1988). Ces films qui, tous, mettent en scène une crise suite à une rencontre avec l'Autre (ou d'autres), plus spécifiquement l'irruption d'un ou des éléments étrangers dans un corps social jamais un mais multiple, divers dans un procès de confrontation/transformation. Cette double contre-ethnographie, portrait de Soi et portrait de l'Autre, ni Soi ni l'Autre n'étant un, mais multiple, divers/divisé est une poéthique (poétique et éthique) liée à un engagement personnel de l'écrivain-cinéaste pour une redéfinition de l'image de l'Afrique sur les écrans. En ce sens, son travail se fait notamment, du moins implicitement, contre un certain cinéma ethnographique dont Jean Rouch a été la figure de proue avec des documentaires comme Les Maîtres fous (1954) ou Mammy Water (1966).
Ce document est protégé par la loi sur le droit d'auteur. L'utilisation des services d’Érudit (y compris la reproduction) est assujettie à sa politique d'utilisation que vous pouvez consulter en ligne.

https://apropos.erudit.org/fr/usagers/politique-dutilisation/ 


\title{
Le cinéma de Sembène Ousmane, une (double) CONTRE-ETHNOGRAPHIE (Notespour unerecherche)
}

\author{
Jeen Jonassaint \\ SyracuseUniversity
}

La plupart des cinéastes africains abordent le cinéma en termes d'éducation et de formation. N ous ne pouvons pas nous permettre de faire du cinéma comme en 0 ccident. Ayant beaucoup d'années de retard, nous avons non seulement à former des hommes mais à faire fusionner des ethnies qui, durant des années, ont coexisté sans se connaître. $\mathrm{C}$ e qui rend notre responsabilité très lourde. M oi-même, je l'avoue, j'ai une très grande peur de la puissance de l'image que j'utilise. A vant d'utiliser chaque image, je suis obligé de calculer, d'imaginer l'impact et la force de cette image sur les spectateurs. Je m'interdis de montrer des travers qui pourraient, le cas échéant, être interprétés autrement.

Si tous les cinéastes raisonnaient de la sorte, nous pourrions avoir un cinéma valable. En tout cas, notre responsabilité est très grande vis-àvis du public. D'autant plus que l'A frique a été longtemps victime des sociologues et des ethnologues.

Sans connaître la culture africaine, ils ont montré des images réelles mais accompagnées de commentaires faux. Ils ne connaissaient ni le sens de la danse ni de la musique. Ils ont collé tout ce qu'ils voulaient là-dessus. L'Européen qui reçoit ça, qui voit l'image et entend le commentaire, se fait nécessairement, une fausse idée de l'A frique et des A fricains.

Ce n'est qu'en prenant conscience de ces problèmes, en mesurant la dualité entre l'image et la parole, que les cinéastes africains feront du bon cinéma. $C$ ependant, il faut dire que le cinéma africain ne sera pas 
authentiquement africain tant qu'il n'y aura pas de politique culturelle bien définie (Sembène O usmane, propos recueillis par Siradiou Diallo 1973: 46) ${ }^{1}$.

Pour éviter quelques malentendus², d'entrée de jeu, je voudrais signaler que je ne suis ni ethnographe ni anthropologue et encore moins spécialiste du cinéma de Sembène 0 usmane, ne connaissant ni le wolof ni le diola ou toute autre langue africaine de ses films, me fiant aux traductions souvent incomplètes : les sous-titres ne s'étendant jamais aux chants qui forment une part significative dans ses longs métrages. Par exemple, dans M oolaadé (2004), même si grâce au rythme, aux mimiques, au contexte, nous nous doutons du contenu du chant de Salba pleurant sa fille, Diatou, morte à la «purification », ignorant la langue de cette complainte africaine, nous ne saurons comprendre pleinement son propos (chapitres 17-18) ${ }^{3}$. II en est de même des chants

1. Ce n'est qu'après la rédaction de la version définitive de cet article que j'ai eu connaissance de ces propos du cinéaste qui semblent bien valider l'analyse de son œuvre comme contre-ethnographie. Pour mémoire, il m'a semblé opportun de les citer intégralement.

2. Je tiens grandement à remercier Catherine Benoît qui m'a permis, entre autres, de mieux cerner les enjeux de l'anthropologie d'hier et d'aujourd'hui. Sans nos discussions parfois vives sur ces questions, cet article serait fort différent. Je voudrais également remercier Francine Saillant qui m'a invité et incité à relever ce premier défi de publier un article sur l'ethnographie et le cinéma de Sembène O usmane. Je dois aussi remercier les divers étudiants qui, au cours des années, ont assisté à mes séminaires sur le cinéma africain à Duke U niversity et à Syracuse U niversity : leurs questions, leurs réflexions, leurs travaux m'ont si souvent éclairé sur les enjeux d'une cinématographie africaine. Je dois un remerciement tout spécial à Isabella A rezzo de la Bird Libray de Syracuse U niversity pour l'aide généreuse qu'elle m'a apportée au cours de la rédaction de cet article, mettant sans réserve à ma disposition les DV Ds des films qu'il me fallait. A u-delà de cette dernière, ma gratitude va à tout un personnel de cette institution, plus spécifiquement celui du prêt inter-bibliothèque qui sans relâche m'aide à trouver les titres les plus rares. U n grand merci au professeur Joseph M iller et à mes collègues du N EH Summer Seminar de 2009 de la Virginia Foundation for the Humanities, "Roots: A frican Dimensions of the History and C ultures of the A mericas », plus particulièrement C.R.D. H alisi et Shannon Rose Riley qui m'ont chaleureusement accueilli ; et au $\mathrm{N}$ ational Endowment for the $H$ umanities pour le support financier qu'il m'a donné pour la recherche et la rédaction de cet article. Enfin, Je suis infiniment reconnaissant à $\mathrm{M}$. A lain Sembène pour m'avoir autorisé à publier des photogrammes de films de son père, à mon collègue et ami Samba Gadjigo pour son aide inestimable.

3. Pour faciliter le repérage des scènes, plutôt qu'un minutage précis qui me semble trop technique, je donne simplement le chapitre où elles se trouvent sur les DV Ds visionnés. Tous les films de Sembène 0 usmane sont analysés à 
des femmes, prisonnières en plein soleil, en réponse à un tirailleur qui vient d'arracher un parasol à deux mères et leurs enfants dans É mitaï (1971). Si un spectateur (ou une spectatrice) ignorant la langue diola peut saisir qu'il s'agit d'une forme de protestation ou de contestation, il ou elle ne peut pour autant comprendre le contenu du texte (voir chapitre 3). Par ailleurs, au passage, il convient de rappeler entre autres les propos de Sembène 0 usmane lui-même sur les limites des traductions. En effet, invoquant la fin de X ala (1974), il dit à J ean et G inette Delmas:

Pour nous, [Xala,] c'est un mythe sur la lutte des classes, et la lutte que la masse doit faire pour renverser la classe bourgeoise. La masse doit aller jusqu'au bout, ce que symbolisent les crachats.En fait, la vraie traduction n'est pas cracher, c'est plutôt vomir, sortir sa bile le mot exact, c'est la bile : il faut « dé-biler » sur la bourgeoisie. C'est une image, un mot populaire et par lemythe, à travers le film, nous faisons un travail que l'écriture journalistique ne pourrait faire parce qu'il est difficile d'écrire les choses d'une manière aussi directe (Sembène O usmane $1976:$ 15).

Les mêmes remarques s'appliquent au mot sénégalais, " ceddo » qu'il reprend pour titrer un long métrage de 1976. En effet, aucune traduction ou expression française ou autre ne saurait rendre toute la charge sémantique ou la polysémie du « ceddo » africain dont il retraçait I'origine historique et la signification en ces termes:

À l'origine, il s'agissait d'un groupe d'individus qui se sont opposés à la pénétration de l'islam pour ne pas perdre leur identité culturelle. $C$ es premiers hommes quirefusèrent de se convertir étaient appelésceddo, "gens du dehors». II s'agit vraisemblablement d'un mot pular.

Le ceddo est un homme de refus. C'est ce refus qui est demeuré à travers les siècles, etqui a donné au mot sa signification. Chez les O uolofs, les Serères, les Pulars être ceddo, c'est avoir l'esprit caustique, êtrejaloux de sa liberté absolue. Être ceddo, c'est aussi être guerrier : parfois combattantpour des causes justes, parfois mercenaire.Le ceddo n'est ni une ethnie, ni une religion, c'est une manière d'être, avec des règles (H ennebelle $1985: 29$ ).

partir de DV Ds édités par la M édiathèque des 3 M ondes (Paris, 2002), sauf les analyses de La $\mathrm{N}$ oire de... et de $\mathrm{M}$ oolaadé qui se font respectivement à partir de l'édition de $\mathrm{N}$ ew Yorker Films ( $\mathrm{N}$ ew York, 2005) diffusé sous le titre de Black Girl ; et Les Films Séville (M ontréal, 2005). Q uant aux films de Rouch, ils sont tous du coffret Jean R ouch, Le G este cinématographique des Éditions M ontparnasse (Paris, 2005). 
$M$ algré ces difficultés évidentes qu'on ne saurait gommer, depuis une vingtaine d'années, je contribue à faire connaître ce cinéma en A mérique du Nord par mes cours ou d'autres interventions extra académiques. Ce travail de diffusion pédagogique m'a permis ou forcé à donner sens à la poéthique singulière (donc une poétique et éthique) qui sous-tend cette œuvre, et expliquer sa différence radicale avec un cinéma hollywoodien omniprésent. Par ailleurs, prenant comme point de référence des films documentaires comme Les M aîtres fous (1954/ 1957) ou M ammy Water (1966) de Jean Rouch ${ }^{4}$ - produits d'une vision plutôt classique de l'ethnologie et du cinéma ethnographique qui se veut un regard (exogène) pour les siens sur un A utre plutôt "statique » et "différent », du moins perçu comme tel (dont Rouch se réclamait encore du moins jusqu'en 1985') - , je compte montrer comment le cinéma de Sembène O usmane qui est regard sur Soi pour Soi dans un procès de confrontation/transformation suite à une rencontre avec I'A utre (ou d'autres) est doublement contre-ethnographique, d'autant plus quand cette plongée dans des mémoires africaines se fait en langues indigènes. C'est d'abord cette lecture plutôt personnelle, notes pour une recherche, que je souhaiterais communiquer à un public plus large que mes salles de classe ou de projection, et ainsi rendre hommage à un géant des temps modernes le très regretté « aîné des anciens » qui insiste dans l'un de ses derniers textes publiés sur l'importance des rencontres avec I'A utre, les autres pour se (trans) former ${ }^{6}$.

\section{Qui est Sembène Ousmane ou Ousmane Sembène ?}

«O usmane Sembène (January 1, 1923- June 9, 2007), often credited in the French style as Sembène 0 usmane in articles and reference works, was a Senegalese film director, producer and writer » (W ikipedia, the free encyclopedia, <http ://en.wikipedia.org/wiki/O usmane_Sembène>, consulté le 16 août 2009).

Sans répéter des informations (élémentaires) qu'on trouve un peu partout sur Sembène 0 usmane, pour l'économie de ce texte, je voudrais

4. Comme le rappelle, entre autres, Faye Ginsburg (2005), ces premiers films doivent être distingués des ethnofictions ou docufictions comme La Pyramide humaine (1961) ou Petit à petit (1970), par exemple.

5. Voir M onique M artineau, Yvonne M ignot-Lefebvre, G uy H ennebelle et A ndré Pâquet 1982.

6. Voir Sembène $O$ usmane qui affirme : « $M$ ais toujours est-il que c'est au contact des autres qu'on se forme. M ême si I'on peut être cruellement, mortellement, déçu» (2007: 196). 
rappeler très brièvement quelques aspects de sa vie et de son oeuvre afin de faire ressortir les rapports entre cette production capitale et la trajectoire du sujet sénégalais O usmane Sembène, devenu le romancier et cinéaste Sembène 0 usmane, et du coup montrer la cohérence interne de son œuvre de La Noire de... (1966) à M oolaadé (2004) qui met en scène une crise suite à une rencontre avec l'A utre (ou d'autres), plus spécifiquement l'irruption d'un ou des éléments étrangers dans un corps social jamais un mais multiple, divers dans un procès de transformation vers un nouvel équilibre. C ette double contre-ethnographie, portrait de Soi et portrait de I'A utre, ni Soi ni l'A utre n'étant un, mais multiple, divers/divisé est une poéthique liée à un engagement personnel que ce regard (panoramique) donnera l'occasion de mettre en lumière.

Sembène O usmane, comme l'écrivain algérien Kateb Yacine, a pris un nom d'auteur qui est un maquillage de son nom de l'état civil. A utrement dit, cet autodidacte qui n'a fréquenté l'école qu'environ six ans, au lieu d'écrire son nom d'auteur suivant la syntaxe de la page couverture, prénom + nom de famille (de l'état civil), a préféré celle des listes d'écoliers où apparaissent d'abord le nom de famille, puis le ou les prénom(s). C'est à la fois une façon de signaler une « dépossession », cette nomination étant une imposition coloniale, notamment de l'école et de l'armée coloniale française dont Sembène O usmane a été un soldat, puisqu'il a été tirailleur sénégalais comme on disait à l'époque. M ais cette (dé)nomination, Sembène 0 usmane, est aussi une façon de la contester, en la détournant, subvertissant du même coup I'usage ou le rituel littéraire. Car nous voilà pris avec un nom d'auteur qui n'est ni tout à fait un pseudo ni vraiment un nom d'état civil, qui pose problème aux bibliographes et critiques - qui doivent se demander où l'entrer, à $S$ ou à 0 ? De fait, ils le rentrent parfois à $S$, parfois à 0 , d'autres fois à $S$ et à 0 .

Par exemple, dans le D ictionnaire des oeuvres du XXe siècle, à l'entrée sur la revue "Présence africaine», nous lisons simplement "Sembene O usmame », mais à l'index on a "SEM BENE O usmane » - noter les capitales à Sembene, sans accent sur le «e » de «bè », l'absence de virgule entre les deux parties du nom (M itterand 1995 : 396, 591). Par contre, dans le $D$ ictionnaire historique, thématique et technique des littératures, l'entrée est à « O USMANE » (Demougin 1986 : 1183), alors qu'à l'index du D ictionnaire des oeuvres littéraires négro-africaines de langue française, il y a une entrée à " O usmane, Sembène » qui renvoie à "Sembène, O usmane », où se trouvent les données (Kom 1983: 637, 658). Dans les deux ouvrages, il importe de noter les virgules qui font 
de «Sembène » et « O usmane » des noms de famille. Quant au tout récent $D$ ictionnaire des cinéastes africains de long métrage de R oy $A$ rmes (2008: 115, 255-256), comme sa version originale anglaise, Dictionary of A frican Filmmakers (2008: 118-119, 229-230), il opte pour «Sembene » comme nom de famille et Ousmane comme prénom d'auteur, suivant ainsi la tradition critique anglo-américaine de refuser, jusqu'à un certain point, à l'écrivain et cinéaste sénégalais le droit de choisir son nom d'artiste comme nous le rappelle implicitement l'entrée de W ikipedia citée plus haut.

La question du nom d'artiste du Sénégalais O usmane Sembène n'est pas des plus simples, lui-même ayant sans doute laissé faire, du moins pour la diffusion des DVDs de ses films aux États-U nis sous le nom de "O usmane Sembene ». Par ailleurs, force est de reconnaître que la Bibliothèque Nationale de France donne comme «forme internationale » : "Sembène, 0 usmane », rejetant la forme «O usmane, Sembène » qu'on retrouve à son catalogue général 1960-19697. C'est également la position du critique Samba Gadjigo (de tous les commentateurs et proches de Sembène Ousmane, sans doute celui qui a le plus contribué à la diffusion de son œuvre aux USA) dans sa biographie 0 usmane Sembène une conscience africaine : genèse d'un destin hors du commun (2007) qui semble choisir de ne pas questionner la prise d'un nom d'artiste si ambigu par le Sénégalais. Est-ce l'influence anglo-américaine qui a porté Gadjigo (qui a étudié aux USA et y enseigne) à s'aligner sur une certaine tradition anglophone de ramener le nom d'artiste au nom de l'état civil «O usmane Sembene » (comme il l'a fait dans un précédent ouvrage collectif en anglais - voir Gadjigo et al. 1993), ou tout simplement, il renvoie à l'homme et son « destin »? Pour ma part, je pense qu'il faut accepter le choix systématique de I'artiste de se présenter sous le (faux)pseudo "Sembène 0 usmane » qu'on retrouve aux génériques et affiches originales de ses films, sur les premières de couverture et pages titres de ses livres en français et général ement en anglais, donc de le traiter bibliographiquement comme un pseudo.

Ce débat sur le nom d'auteur peut paraître sibyllin. Mais I'inconsistance du catalogue en ligne de la British Library (consulté le

7. Voir le catalogue en ligne de la BNF (consulté le 9 août 2009) à : http:// catal ogue. bnf. frservletautorite? $\mathrm{D}=11924383 \&$ idN oeud=1.1\& host=catal ogue. 
31 août 2009) ${ }^{8}$, ou plutôt son souci de refléter l'inconsistance des éditeurs anglophones de Sembène O usmane, notamment $\mathrm{H}$ einemann qui le publie parfois sous le nom d'auteur, Sembène Ousmane, d'autres fois sous son nom de naissance, 0 usmane Sembène, porte du moins à réfléchir. Par ailleurs, quand on constate que son éditeur français, Présence africaine, publie en 1972 un ouvrage de Paulin Soumanou Vieyra (qui fut le directeur de production du cinéaste), titré en première de couverture, Sembène 0 usmane cinéaste et sur la tranche Sembène 0 usmane, mais devient en page de faux-titre, 0 usmane Sembène cinéaste, et en page de titre, 0 usmane Sembène cinéaste Première période 1962$1971^{9}$, on comprend mieux le flou autour de ce nom d'auteur, et l'importance de cet essai de clarification. En effet, ce seul ouvrage est parfois cité "Sembène 0 usmane cinéaste » et d'autres fois comme «O usmane Sembène cinéaste $»^{10}$. Comment se retrouver dans cette valse de variations sur un nom d'auteur?

Un deuxième élément biographique à retenir sur cet écrivain et cinéaste sénégalais, c'est un autodidacte : tour à tour pêcheur, soldat, docker, militant syndical, romancier, cinéaste. II a été à l'école de la vie, et son oeuvre en porte l'empreinte, notamment son premier roman, Le Docker noir (1956), qui est sous certains aspects autobiographiques, mais surtout son approche pragmatique de la littérature et de l'art en

8. Par exemple, pour le même titre, G od's Bits of Wood (la traduction anglaise de Les Bouts de bois de Dieu par Francis Price), publié la même année (1970), par le même éditeur (H einemann), nous avons deux entrées avec de noms différents: "Sembène, O usmane » et "OU SM A N E, Sembene » [sic]. II en est de même des éditions françaises de N iiwan (Présence africaine 1987 et 2001) qui sont listées sous des noms d'auteur différents, respectivement, « Sembène, O usmane » et «O usmane, Sembène » (sans les capitales à O usmane).

9. L'édition française de Ô pays, mon beau peuple! publiée par Presses Pocket en 1975 présente aussi une incongruité plus ou moins similaire. En effet, en première et quatrième de couverture, nous lisons «O usmane Sembene », mais «Sembene Ousmane » [sic] en page titre.

10. Par exemple, Martin Bestman (1974) dans un compte rendu pour une revue universitaire québécoise, titre l'ouvrage et son texte "Sembène O usmane cinéaste ». Samba Gadjigo également des années plus tard sur son site W eb consacré à "O usmane Sembène, Senegal's most admired film maker of the century », liste l'ouvrage de Vieyra sous le titre de "Sembène O usmane cinéaste » - voir, C ritical W orks <http://www.mtholyoke.edu/courses/sgadjigo/ page30/page30.html>. Par contre, la Bibliothèque nationale de France, comme le catalogue en ligne W orldC at, donne comme titre, O usmane Sembène cinéaste : première période 1962-1971. 
général comme il l'exprime si bien dans ses entretiens de 1968 avec Guy Hennebelle :

Ce qui m'intéresse, c'est d'exposer les problèmes du peuple auquel j'appartiens. Je ne cherche pas à faire du cinéma pour mes petits copains, pour un cercle restreint d'initiés.... Pour moi, le cinéma est un moyen d'action politique. Sur le plan idéologique, je me réclame du marxisme-léninisme. M ais à ce sujet, je tiens à ajouter deux choses: d'une part, je ne veux pas faire un cinéma de pancartes; d'autre part, je ne pense pas qu'il soit possible de changer une situation donnée avec un seul film. Simplement, je crois que si nous, cinéastes africains, tournons une série de films orientés dans le même sens, nous parviendrons à modifier un tout petit peu les forces en présence, en développant la prise de conscience du peuple. J'aime Brecht et j'essaie de m'inspirer de son exemple (Hennebelle 1968 : 5-6).

En fait, ce que Sembène O usmane rappelle ici avec beaucoup de force, de courage et de conviction, c'est son refus de l'art pour l'art, autrement dit son engagement sans pour autant renier la dimension esthétique, sans tomber dans l'art de propagande. II pense que le cinéaste, comme l'écrivain, doit «participer à la libération des peuples» avec tous les outils à sa disposition, sans exclusive. A ussi, il ne partage pas le point de vue de ceux qui refusent la caméra comme invention des blancs ou toute alliance avec les ex-colonisateurs. Sur ce point, répondant à une question de $\mathrm{H}$ ennebelle sur les avances sur recettes qu'il avait reçues du gouvernement français pour Le $M$ andat, il va jusqu'à déclarer : " dans l'état actuel des choses, je suis prêt à m'allier au diable, tout en étant décidé à ne renier aucune de mes convictions politiques ». De plus, cet engagement culturel est important pour l'A frique en lutte, et doit se situer au-delà de tout parti pris racial ou ethnique, en ce sens, il se distingue nettement du courant de la négritude. II ne cherche pas à célébrer une A frique ancestrale ou mythique, et encore moins une africanité de façade ${ }^{11}$. II est un écrivain et un cinéaste pragmatique qui cherche à communiquer avec son peuple pour donner à lire ou à voir là où le bât blesse qu'importe l'origine, qu'importe les responsables, en quête de compréhension et de solution. A ussi, pour lui, « un film, c'est un débat, ce n'est pas seulement un film ». II ajoute :

11. Voir l'introduction à Véhi C iosane ou Blanche-G enèse où il explique pourquoi il a écrit cette histoire d'inceste malgré l'opposition de ses confrères africains qui y voient une arme entre les mains des ennemis de l'A frique; voir Sembène O usmane 1965 : 15-17. 
Il faut que le cinéma soit une école du soir pour ceux qui veulent réfléchir doivent y trouver des éléments de réflexion pour pouvoir aller de l'avant....

On discute tous les jours du film.... N ous allons dans les écoles, chaque lycée à une salle, vous appelez ça ciné-club, nous appelons ça salle de réflexion. On vient, on présente un film et on discute du film.... Mais nous sortons du film, nous ne discutons pas seulement du film. Le film conduit à la discussion. N ous discutons de la bourgeoisie et comment on devient mendiant dans un pays, voilà. N ous parlons des paysans et ainsi de suite. Ça déborde le cadre du film. Et ça donne à la discussion un caractère concret. $M$ ême la critique au réalisateur. $M$ oi je suis obligé tous les mois, deux fois par mois, de passer sous la douche devant le public (Sembène O usmane 1976 : 15-16).

C ette volonté de débattre, d'échanger sur le film ou même de défier le réalisateur, pour une transformation ne se manifeste pas seulement hors scène (après la projection), elle est également sur scène, partie intégrante du cinéma de Sembène O usmane. En fait, I'un des traits récurrents de ses films, notamment depuis É mitaï (1971) - qui raconte I'affrontement d'un village, plus particulièrement de ses femmes avec l'armée coloniale française sur un mode quasi silencieux, ne s'exprimant que par gestes ou des chants - est la mise en scène d'une confrontation ou d'une suite de confrontations verbales ou débats. Cette poéthique de la confrontation ou du débat, de la joute oratoire qui n'est pas sans rappeler des «palabres» dont la première manifestation évidente est dans la fin de Xala (1974) avec les procès de El Hadj A bdoukader Beye par les hommes d'affaire à la chambre de commerce et les mendiants chez lui, atteint un apogée avec C eddo (1976) qui est structuré comme un long procès de l'islam dogmatique sur la place d'un village africain au $18^{e}$ siècle ${ }^{12}$. Elle sera reprise avec des variantes dans les films subséquents, notamment C amp de Thiaroye (1988), G uelwaar (1992) et M oolaadé (2004) - voir photogrammes A 1-A 4.

12. En fait, bien que fon dé sur des faits historiques, il y a dans $C$ eddo une imprécision voulue sur le temps de I'histoire qui se traduit parfois par l'anachronisme de certains objets du film : le parasol du Roi, les fusils des protagonistes entre autres. Sur ce point, dans une entrevue avec Guy $\mathrm{H}$ ennebelle, le réalisateur affirme: « Lefilm est situé au XV II e ou XVIII e siècle, maisil n'est pas exactement daté. J'ai surtout voulu que ce soit un film de réflexion, afin que nous, A fricains, ayons le courage d'essayer de réfléchir sur notre propre histoire et les éléments que nous avons reçus de l'extérieur et que nous cessions de faire des films pour pl eurer sur notre misère ou soll iciter la condescendance des autres » (H ennebelle 1985 : 29). Pour une analyse détaillée des rapports de Ceddo à I'histoire (officielle ou non), voir Mamadou Diouf 1997. 

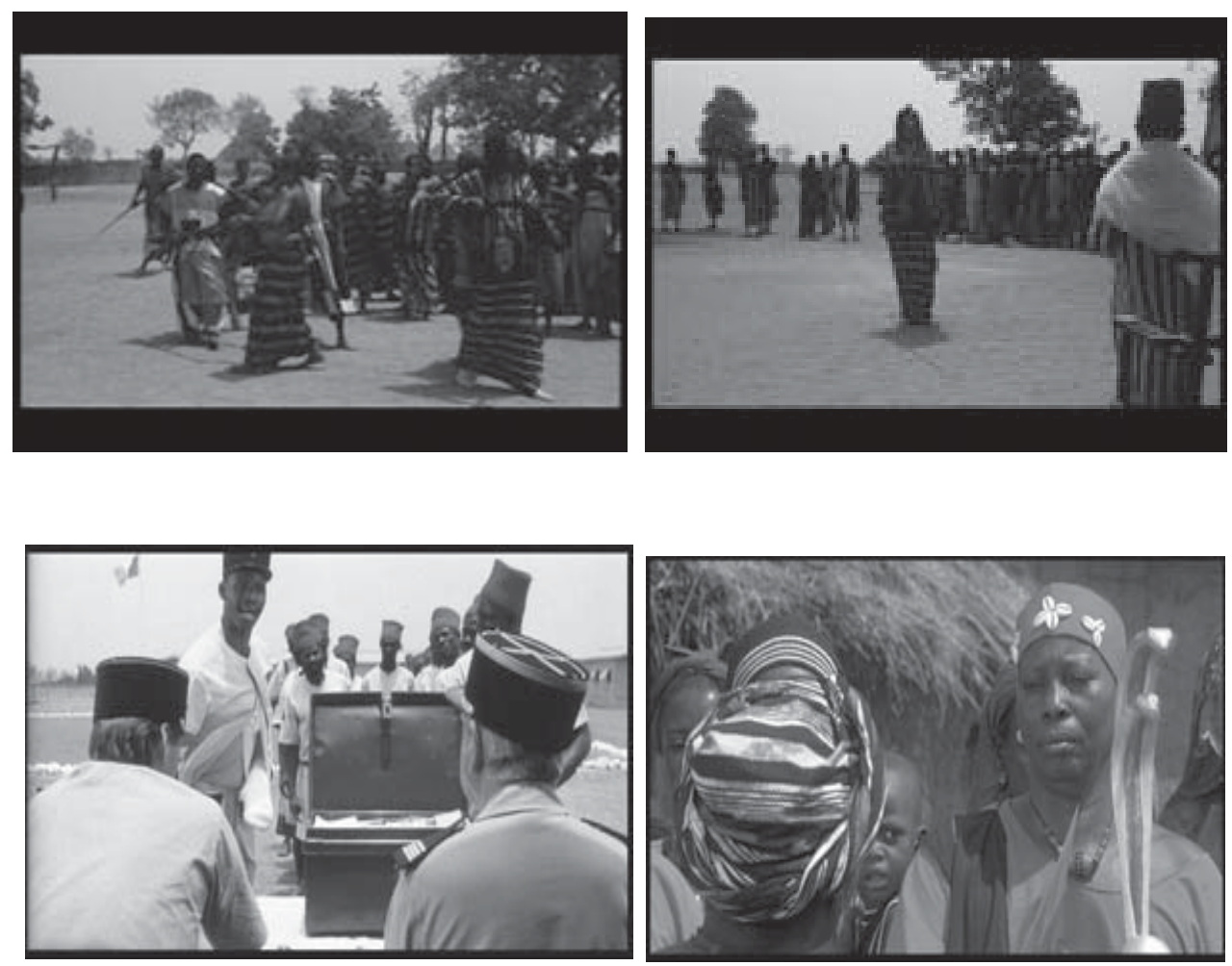

A 1-2. C eddo, la dernière scène, revirement de situation au retour de Dior Yacine qui tue I'Iman.

A 3. C amp de Thiaroye, des officiers de l'armée coloniale française confondus par une harangue du serget-chef Diatta.

A 4. M oolaadé, la chef des exciceuses sous la menace des mères en révolte.

Photogrammes publiés avec l'aimable autorisation de M. A lain Sembène.

Tous droits réservés.

Le dernier élément sur lequel il convient d'insister, sans doute le plus important, c'est le rapport étroit entre l'évolution de son œuvre, et le contexte historique et social dans lequel elle s'inscrit. Plus particulièrement, il importe de souligner comment cette évolution se fait en fonction de ce pragmatisme militant qui est central dans sa conception du travail artistique ou littéraire, et se traduit dans le choix de ses titres, du moins leur langue, les thématiques et formes ou genres de ses oeuvres. 
A u premier coup d'oeil, on constate que Sembène 0 usmane a publié son premier roman, Le Docker noir (1956), avant les Indépendances africaines, et son dernier titre, G uelwaar, date de $1996^{13}$. De fait, il est avec le Camerounais M ongo Beti, auteur entre autres du fameux pamphlet contre les nouveaux dirigeants africains, $M$ ain basse sur le C ameroun (1972), I'un des rares romanciers francophones africains (au sud du Sahara) à avoir publié plusieurs titres avant et après les Indépendances.

Entre 1956 et 1960, I'année des Indépendances africaines, Sembène Ousmane qui vit en France publie trois romans qui sont relativement longs, plus de 200 pages pour les deux premiers, et près de 400 pour le dernier. Ces trois romans portent principalement sur le colonialisme, bien que le premier, Le Docker noir, soit aussi un texte sur l'immigration et l'appropriation tant de la force de travail du migrant (colonisé) que ses expressions esthétiques, plus particulièrement ici son écriture (vol d'un manuscrit d'un docker noir par une éminente romancière française qui est tuée par ce dernier pour ce méfait) ${ }^{14}$. Les titres de ces romans sont tout à fait français, sauf le dernier, Les Bouts de bois de D ieu, qui est une traduction littérale de son sous-titre wolof : "Banty Mam Yall», les hommes. Par ce recours manifeste à une autre langue d'une autre culture, et à cette traduction qui n'en est pas une, s'introduit un écart significatif. L'expression « les bouts de bois de Dieu » ne fait pas sens en français. Du moins, elle ne dit pas ce que l'écrivain exprime dans sa langue, les hommes (Banty $\mathrm{M}$ am Yall). II me semble qu'ici il veut attirer l'attention du lecteur occidental sur le fait qu'il a un langage propre, avec ses propres formes ou expressions qui ne sont pas réductibles.

13. Pour une vue globale rapide sur la production de Sembène 0 usmane, voir sa bibliographie et filmographie en annexe. Pour des résumés de ses œuvres et extraits de ses films, voir le site W eb du professeur Samba Gadjigo, «O usmane Sembène, Senegal's most admired filmmaker of the century » : <http:// www.mtholyoke.edu/courses/sgadjigo/index.html>.

14. À noter, bien que ce roman soit jusqu'à un certain point de l'ordre de l'autobiographique, le vol de manuscrit qu'il rapporte ne semble pas fonder sur la biographie de l'auteur. Dans les faits, sel on Samba Gadjigo, notre écrivain a plutôt bénéficié de l'aide généreuse de camarades français dont 0 dette $A$ rouh qui corrigeait son manuscrit à mesure qu'il avançait dans sa rédaction. D'ailleurs, ce roman, comme son second, Ô pays, mon beau peuple (1957) est dédié, entre autres, à « 0 dette» - voir Gadjigo (2007 : 224). 


\section{Vers le cinéma, pour une contre-ethnographie}

L'affirmation d'une prééminence subjective du wolof sur le français, pour reprendre une formule d'A lioune Tine ${ }^{15}$, ou plus spécifiquement d'une certaine titrologie africaine sur une française, pas seulement sur le plan linguistique, mais plus largement langagier, est des plus évidentes dans les titres des années 1962-1965 qui sont un syntagme africain, V éhi C iosane, ou un terme africain francisé, I'H armattan, ou un mot français africanisé, Voltaïque. M ais ce qui est fondamental ici, c'est qu'après son retour en A frique en 1961, c'est le changement de forme et de problématique. Délaissant le conflit colonial (sans oublier le choc des cultures qu'il a engendré) pour interroger d'abord les nouveaux dirigeants africains et certaines traditions africaines (changement thématique), Sembène O usmane passe d'une part à la nouvelle (Voltaïque) ou au court récit (Le M andat et Véhi C iosane) ; d'autre part au cinéma qui deviendra après le succès du film La Noire de... (1966) sa forme d'expression privilégiée, conscient que le cinéma lui permet de mieux communiquer les préoccupations de son peuple, et aussi de mieux communiquer avec son peuple qui est analphabète (double changement sur le plan formel).

En effet, de retour au Sénégal, il découvre un fait troublant, il n'existe pas comme écrivain en A frique, il n'est pas lu, il n'est pas connu, et pour cause, I'A frique connaît à l'époque des taux d'analphabétisme pouvant atteindre $99 \%$. D'où son questionnement : comme écrivain engagé, comment atteindre ce public (qui est le sien) qui n'a pas accès au livre? Et pour lui, la meilleure façon de le faire, c'est avec le film, le cinéma. Et très vite, il comprendra qu'il faut le faire en langue africaine, d'où son choix en 1968 du wolof pour son premier vrai long métrage ${ }^{16}$, $M$ andabi.

Cette volonté de mieux communiquer les préoccupations du continent africain, et aussi de mieux communiquer avec ses habitants qui est centrale dans sa démarche est fort bien illustrée par l'adaptation cinématographique de La Noire de... Si dans la nouvelle, I'histoire de

15. Voir l'article de Tine (1985), d'où je reprends en partie des éléments biographiques et analytiques sur la vie et l'œuvre romanesque de Sembène O usmane.

16. La $\mathrm{N}$ oire de... bien que produit comme un long métrage de 90 minutes, pour éviter des tracasseries administratives, a été commercialisé comme un moyen métrage de 60 minutes. Sur cette question, voir G uy Hennebelle (2008 : 9). 
Diouana s'inscrit entièrement dans I'A frique coloniale en lutte, le texte s'ouvrant sur sa mort le " 23 juin de l'an de grâce $1958 »^{17}$, Le film quant à lui place l'histoire dans le contexte postcolonial, celui de I'assistance technique, de la néo-colonisation comme le rappelle si bien la scène du repas où $M$. explique à un jeune couple les avantages extraordinaires, garantis par des solides accords de coopération, pour un Européen travaillant en A frique, notamment au Sénégal (chapitre 3).

De plus, contrairement au texte qui, d'entrée de jeu, met en place les deux mondes qui s'affrontent, celui des baigneurs insouciants de la plage d'A ntibes, et celui des peuples en lutte contre le colonialisme, le film s'ouvre sur une sorte d'image d'Épinal d'un paquebot arrivant en rade (en France) ${ }^{18}$. M ais cette image est signe tant de la néo-colonisation que de la migration notamment Sud/Nord. En effet, le tourisme, particulièrement la croisière étant l'une des formes les plus généralisées de l'entreprise néocoloniale, et l'immigration, un symptôme assez manifeste de l'échec des Indépendances et de la désillusion postcoloniale qu'il mettra encore mieux en évidence avec le roman Le M andat (1965) et son adaptation cinématographique $M$ andabi $(1968)^{19}$ qui raconte les

17. Pour mémoire, rappelons entre autres que 1958 est l'année du Référendum sur les colonies françaises d'A frique (28 septembre), donc qui marque la fin de I'U nion française (1946-1958), annonce les Indépendances à venir en 1960, et a inspiré à Sembène 0 usmane, I'un de ses grands romans, L'H armattan. Référendum. Certes, c'est aussi du point de vue de l'histoire de la France métropolitaine, la naissance de la Ve République, mais ce n'est là qu'un point secondaire pour notre propos.

18. Cette comparaison de la nouvelle, «La N oire de... » avec le film qui en est tiré bien qu'elle recoupe par endroits celle déjà classique de Françoise Pfaff, « Black G irl (1966) : From Text to Film», dans The Cinema of O usmane Sembene, A Pionner of A frican Film (1984), s'en écarte nettement tant dans le choix des scènes que la finalité de l'analyse. Par ailleurs, il convient de noter qu'une première version plus développée de cette analyse comparative a bénéficié de mes échanges avec la professeure $\mathrm{N}$ icoletta Pireddu qui m'avait invité à donner une conférence sur les « $N$ oire de... de Sembène $O$ usmane » à son séminaire de littérature comparée à G eorgetown U niversity, le 2 décembre 1998.

19. II existe deux versions de ce film, I'un en français, Le M andat, I'autre en wolof, titré, $M$ andabi. C'est cette dernière version qui est la plus diffusée et la mieux connue. C'est également elle que nous analysons, bien que nous la nommons parfois par commodité improprement, Le M andat. À noter, selon Samba G adjigo (entretien téléphonique du 19 septembre 2009), que le projet de film a précédé le roman, mais des problèmes de financement ont poussé Sembène 0 usmane à compléter et publier le roman d'abord. 
déboires d'un chômeur illettré, Ibrahima Dieng, dans les dédales bureaucratiques de Dakar pour encaisser un mandat reçu d'un neveu de Paris.

D'autre part, si le récit laisse entendre la voix d'un narrateur impersonnel qu'un lecteur tend à identifier avec un auteur (romancier ou ethnographe), dans le film, c'est plutôt celle de Diouana (voix de la dominée, de l'observée qui se fait observatrice par la force des choses), bien que off, qui domine. C'est à travers sa conscience, sa mémoire, non à partir de celle de $M$ me (l'étrangère lettrée, celle qui traditionnellement observe, commente) comme dans la nouvelle, que nous reconstituons les faits. A ussi, le film part de son arrivée en France en bateau à sa mort, plutôt que du constat de sa mort comme dans le récit. Ce changement de perspective permet de mettre en valeur la femme noire, et de faire de Diouana une vraie héroïne, tragique certes, mais héroïne tout de même au sens le plus classique du cinéma. Car comme l'a rappelé Sheila Petty : « [Diouana] écrase par sa seule présence les autres personnages du film. Elle est présente dans toute l'action du film, donnant une unité au récit » (Petty 1991 : 127).

Par ailleurs, ce passage du il (d'un narrateur omniscient) au je (d'une narratrice personnage principal), donc d'une certaine ou prétendue objectivité à une certaine ou prétendue subjectivité n'est pas sans conséquence. Elle implique un regard de Soi sur Soi, un regard sur l'A utre pour Soi qui donne à voir et entendre un processus de prise de conscience : la transformation de Diouna se rappropriant et transcendant ses manières de faire et d'être, donc s'exprimant pleinement. Elle se fait même juge de ses juges, ici ses patrons français dénommés anonymement $M$. et $M m^{20}$. C 'est un moment fort d'une contre-ethnographie, où le discours de l'observé/dominé sur l'observateur/dominant normalement tu, sinon ignoré21, s'exprime avec force : «M adame m'a menti. Elle m'a

20. Ici manifestement, le film, comme la nouvelle d'ailleurs, prend le contre-pied des conventions qui font des domestiques des sans noms en prénommant la bonne, Diouna, et en taisant systématiquement les noms de ses patrons qui tombent dans l'anonymat de ceux réduits à leur fonction.

21. Bien que l'on sache, pour reprendre une formule de Michel Izard que «plus ou moins à son insu, l'ethnologue est observé, jugé, jaugé » (voir Izard 2007 : 474), généralement, il me semble que cette parole autre n'est pas retransmise dans le discours ethnographique classique. M ême des films de Jean Rouch comme La Pyramide humaine (1961) ou Petit à petit (1970), qui donnent voix à des $\mathrm{A}$ fricains sur l'Europe et les Européens en général, ne vont pas jusqu'à juger Rouch, lui-même comme observateur, qui tout compte fait dans ses 
toujours menti... Jamais plus elle me mentira. Elle voulait me garder ici comme une esclave», dit-elle dans son dernier monologue (chapitre 16). Faisant suite à son « $Q$ u'est-ce qu'ils mangent et radotent ces gens ! Ils ne font que boire » lors du dîner (chapitre 3), la reprise de son don à madame en scandant «C e masque est à moi ! ( (chapitre 12), et sa confrontation musclée avec sa patronne qui tente de se rapproprier le masque (chapitre 15), ce cri est sans équivoque. Elle refuse d'être «la noire de ». Elle range ses habits dans sa valise, se défait de la perruque qu'elle prisait tant avant, se coiffe de tresses africaines, se prépare pour son suicide se disant à elle-même : "Jamais plus $\mathrm{M}$ me ne me verra !... Jamais plus de Diouna! Jamais plus je ne les verrai moi aussi » (chapitre 16). Elle sort définitivement de l'« esclavage domestique » où elle était acculée en France pour renouer, au-delà des siècles et de l'espace, avec la geste légen daire des esclaves noirs d'A mérique, car ce n'est sans doute pas par hasard, malgré les contradictions et questions que ce choix peut soulever ou soulève, que la voix de Diouna soit celle d'une comédienne haïtienne, Toto Bissainthe. Et notre cinéaste africain, à son tour de s'approprier d'une image emblématique des plus connues de I'histoire et de l'art français, le M arat assassiné de J.-L. David (1793) pour immortaliser le geste de Diouna la gorge tranchée dans sa baignoire le rasoir tombant de sa main, mais ce n'est qu'une première image du drame, celle qui suit rappelant plutôt des corps d'esclaves dans la cale d'un navire négrier (voir photogrammes B1-B4). U ne telle composition de l'image comme une toile d'un grand maître de la Révolution française ou d'un symbole des luttes anti-esclavagistes des $18^{\mathrm{e}}$ - $19^{\mathrm{e}}$ siècles, est fort significative : le suicide se lit comme un assassinat (ou un génocide) et s'inscrit au-delà de l'histoire d'une bonne (ou du fait divers qui l'a inspiré) dans la grande histoire des luttes humaines contre l'oppression. D'autre part, il s'agit d'un renversement radical, ce n'est pas le dominant qui s'approprie des outils ou savoirs du dominé, mais le dominé, I'A fricain, qui fait sien les outils et savoirs des colonisateurs français pour parler de lui, de sa rencontre avec cette France qui devient objet d'investigation. Ce sont là deux fondements de la contre-ethnographie que Sembène O usmane élabore pour les siens d'abord, mais aussi implicitement, sinon consciemment, contre Jean Rouch ${ }^{22}$ qu'il avait accusé de les présenter

docufictions ethnographiques ou ethnofictions avait, comme réalisateur, le dernier mot.

22. Il importe de rappeler que l'un des tout premiers films de Sembène Ousmane, ironiquement jamais diffusé, sinon inachevé, porte sur l'E mpire Songhaï dont Rouch a Ionguement étudié notamment dans sa grande thèse d'ethnologie publiée en 1960. 

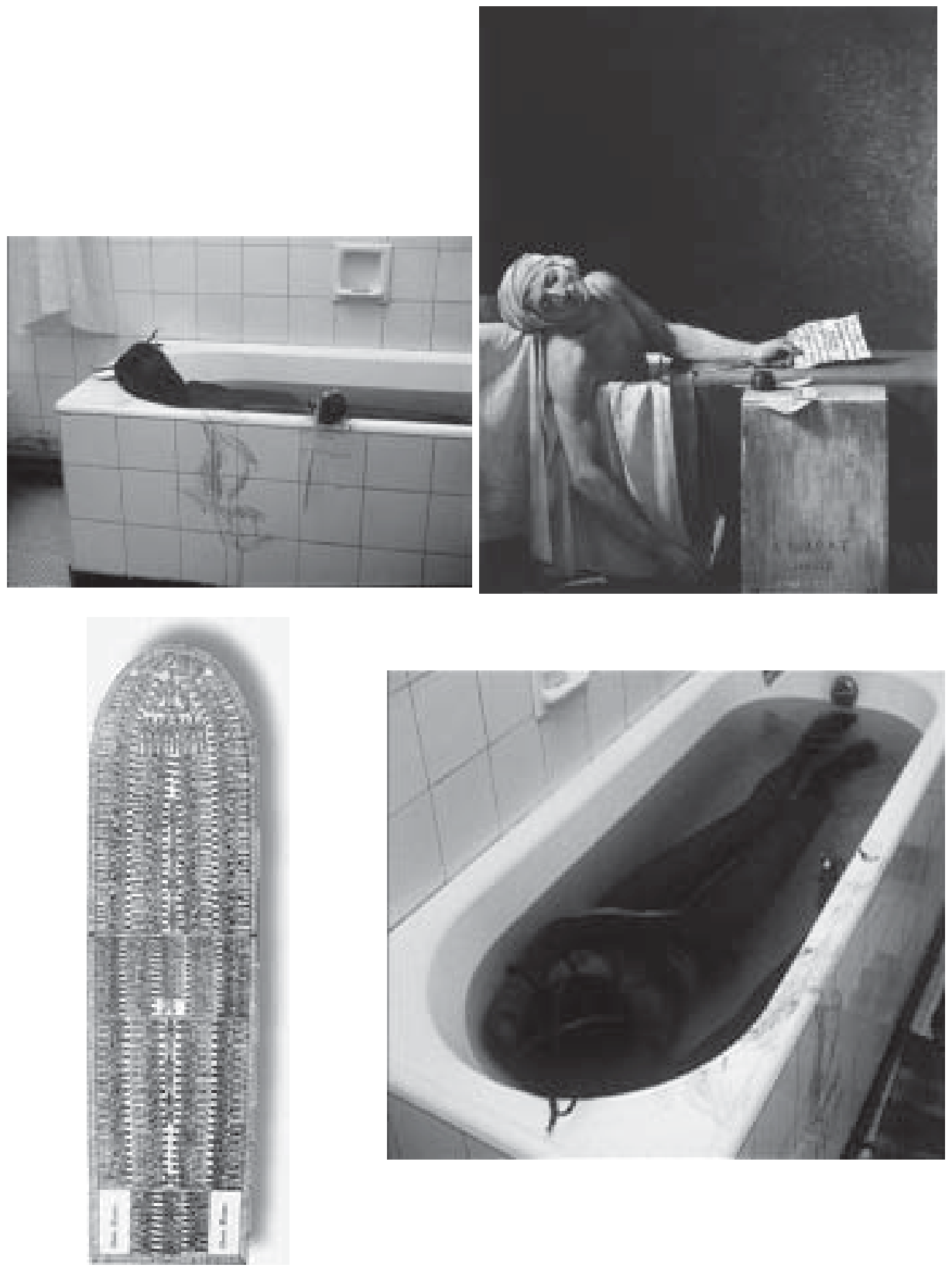

B1. La N oire de..., Diouna mourante, un rasoir à la main.

B2. M arat A ssassiné de David.

B3. Coupe d'un navire négrier.

B4. La noire de..., Diouna morte dans la baignoire.

Les photogrammes de La N oire de... sont publiés avec l'aimable autorisation d'A lain Sembène. Tous droits réserrvés. 
« comme des insectes» dans une « confrontation » de 1965 entre les deux cinéastes, ou un certain cinéma qui faisait des $A$ fricains des curiosités, au mieux des figurants.

Dans cet échange, Rouch soutient explicitement la démarche classique de l'ethnologie, affirmant : " je dispose d'un avantage et d'un inconvénient à la fois, j'apporte l'œil de l'étranger. La notion même d'ethnologie est basée sur l'idée suivante: quelqu'un mis devant une culture qui lui est étrangère voit certaines choses que les gens qui sont à l'intérieur de cette même culture ne voient pas. » À cela, Sembène Ousmane réplique: "Tu dis voir. M ais dans le domaine du cinéma, il ne suffit pas de voir, il faut analyser. Ce qui m'intéresse c'est ce qui est avant et après ce que l'on voit. Ce qui me déplaît dans l'ethnographie, excuse-moi, c'est qu'il ne suffit pas de dire qu'un homme que l'on voit marche, il faut savoir d'où il vient, où il va.... » (Cervoni 1982 : 77). II est donc évident que ce qui gêne le cinéaste africain - qui demandait juste avant à Rouch s'il comptait " continuer à faire des films sur l'A frique » quand il « y aura beaucoup de cinéastes africains » (C ervoni 1982 : 77) - , c'est aussi, sinon plus, ce regard extérieur qui se veut neutre, du moins non partie prenante d'une démarche explicative et transformatrice. II donne en exemple, Les Fils de l'eau (1952) dont «beaucoup de spectateurs européens n'y ont rien compris parce que ces rites d'initiation, pour eux, n'avaient aucun sens. Ils trouvaient le film beau, mais ilsn'y apprenaient rien. » Rouch implicitement acquiesce à cette remarque, et donne en exemple, Les M aître fous (1954) dont « la diffusion... a été réservée à des cinémas d'art et d'essai, et à des ciné-clubs», car il croit "qu'il ne faut pas apporter de tels films à un public trop large, non informé, et sans présentation, sans explication » (Cervoni 1982 : 78). On pourrait également citer l'absence complète d'explication (ou même de mise en contexte) de la croix gammée inversée sur une voile d'un bateau de pêcheurs dans une séquence vers la fin de M ammy Water (1966) de Rouch qui contraste avec les longues explications et contextualisations de l'attachement obsessionnel de Pays au casque nazi dans Camp de Thiaroye. D'un côté, il y a une appropriation, si appropriation il y a, qui semble statique, «aliénante», d'un signe de l'autre, il y a un usage dynamique, dialectique d'un symbole nazi pour montrer, entre autres, le parcours douloureux d'un personnage, et du coup signifier I'horreur du fascisme. C'est là un aspect fondamental de la contre-ethnographie sur lequel il convient d'insister, car justement, selon le cinéaste sénégalais, ce qui lui déplaît dans l'ethnographie, c'est 
le manque de perspective historique : son refus de voir l'avant et de projeter l'après.

Bien que depuis la «confrontation » de 1965, selon la présentation des extraits republiés par $C$ inémA ction, Sembène O usmane "s'est refusé à toute déclaration sur le cinéma de Rouch », comme en 1973 dans sa Iongue entrevue avec Siradiou Diallo pour Jeune A frique, dans un entretien avec Guy Hennebelle des années plus tard, parlant de son court métrage, Taw, il réaffirme implicitement son refus du cinéma ethnographique, plus particulièrement du «cinéma-vérité ». En effet, dit-il : «... Taw, un court métrage, [qui] m’a été commandé par le Conseil œcuménique des Églises (U.S.A.). II s'agissait d'évoquer le problème des jeunes à Dakar et de dresser en somme un bilan de dix ans d'indépendance de leur point de vue. J'étais mal à l'aise au départ car je ne suis pas documentariste et je ne crois pas beaucoup au «cinémavérité » (Hennebelle 1985 : 26) ${ }^{23}$. Par ailleurs, Rouch également des dizaines d'années plus tard ne digérait pas plus le cinéma militant ou d'intervention auquel Sembène 0 usmane s'identifie. II le considère comme n'étant pas du cinéma, ne connaissant pas « d'exemple réussi de cinéma militant ... sur le plan cinématographique ». Et plus loin, répondant à cette question de Guy Hennebelle ( « Je crois que ce qui te déplaît dans un certain cinéma militant, c'est la présence d'une conception globale... »), il ajoute : «Non, qu'il y ait des réponses! Je

23. Dans ce même numéro de C inémA ction, Rouch donne une entrevue à Pierre $\mathrm{H}$ affner, où il parle de son amitié avec le Sénégalais et son admiration pour certains de ses films (voir : H affner 1985). Sembène O usmane aussi a évoqué publiquement son amitié avec Rouch, mais c'était chaque fois pour signaler du même souffle qu'il «n'aimait pas ses films » qui ne « lui convenaient pas» ou pour rejeter son cinéma-vérité (voir entre autres $A$ nnett Bush et $M$ ax $A$ nnas 2008 : 16, 23, 48, 58 ; des entrevues de 1969 et 1971 avec Guy Hennebelle, celles de 1972 avec Peary et McGilligan). Par ailleurs, selon Samba Gadjigo (entretien téléphonique du 19 septembre 2009), Iors de sa leçon de cinéma au Festival de Cannes (15 mai 2005), Sembène O usmane aurait reconnu, entre autres, l'importance du cinéma de Rouch pour sa démarche. Mais il n'y a aucune référence à Rouch dans le texte de la « leçon » publié dans L es L eçons de cinéma, édition établie par A ntoine de Baeque (2007 : 193-200). Par contre, il reconnaît ses dettes entre autres envers les cinéastes C haplin, De Sica, Truffaut, et le critique Georges Sadoul qui lui a permis d'aller étudier le cinéma à Moscou, et affirme d'entrée de jeu être «devenu celui par qui les images de I'A frique sont arrivées en Europe ». Comment nier plus catégoriquement le travail de Rouch ? Cela dit, la complexité de la relation Sembène/ Rouch mériterait plus de recherches qui manquent singulièrement. 
n'aime pas qu'on prétende détenir la vérité ! » (Martineau et al. 1982 : 172-173, 175). M ais pour les deux cinéastes, il importe de donner voix aux A fricains, comme le montrent bien certains films de Jean Rouch comme $\mathrm{M}$ oi un $\mathrm{N}$ oir (1959) dont Sembène O usmane affirme qu'un «A fricain aurait pu le faire » (Cervoni 1982 : 77) ; La Pyramide humaine (1961), regards croisés sur des Européens et A fricains en A frique; La C hasse au lion à l'arc (1965) qui donne à voir la complexité de tout un savoir-faire africain (de la maîtrise du fer à celle des végétaux en passant par une connaissance exemplaire de la faune) ; Petit à Petit (1970) qui est tout à la fois une amusante ethnographie de la France par des A fricains et un regard critique sur les voies de développement en A frique. En ce sens, le cinéma ethnographique de Rouch qui se veut des « objets inquiétants » pouvant agir sur « la conscience du spectateur européen » ( $M$ artineau et al. 1982 : 166) est fort différent d'un certain cinéma colonial des années 1950-1960. Pourtant, il y a tout de même des divergences profondes entre les projets cinématographiques du Français et du Sénégalais. Jusqu'à un certain point, nous faisons face à deux positions irréductibles aux finalités entièrement divergentes : un cinéma documentaire (ethnographique) fait par un universitaire étranger (européen) qui veut archiver le monde (africain) pour un public européen ; et un autre militant (de fiction) fait par un autodidacte (africain) qui veut transformer le monde (africain) pour un public africain. A ussi, ce n'est pas par hasard que le rapport entre filmants et filmés soit radicalement différent d'un cinéma à l'autre : Rouch I'universitaire européen filmant des A fricains impose dans sa langue française sa voix off pour donner sens aux images, Sembène O usmane I'autodidacte africain filmant des $A$ fricains dans leurs langues diverses fait corps avec les siens pour transformer son monde au contact des A utres. A insi, il est acteur parmi les acteurs, fondu dans la masse des personnages : ceddo parmi les ceddos dans le film du même nom ou écrivain public dans Le $M$ andat, par exemple (voir photogrammes C 1-2).

Ce regard sur Soi dans sa rencontre avec I'A utre (dominant) implique un renversement et un détournement qu'illustre bien $\mathrm{C}$ amp de Thiaroye. Plus que dans La N oire de... ou É mitaï, dans ce film coréalisé avec Thierno Faty Sow, Sembène 0 usmane fait des observateurs autorisés d'antan des objets d'investigation d'aujourd'hui, et s'approprie d'objets emblématiques de l'histoire européenne pour décrire les siens. D'une part, d'un film, qui au prime abord raconte le retour de la deuxième guerre mondiale de tirailleurs sénégalais, il en fait une critique 

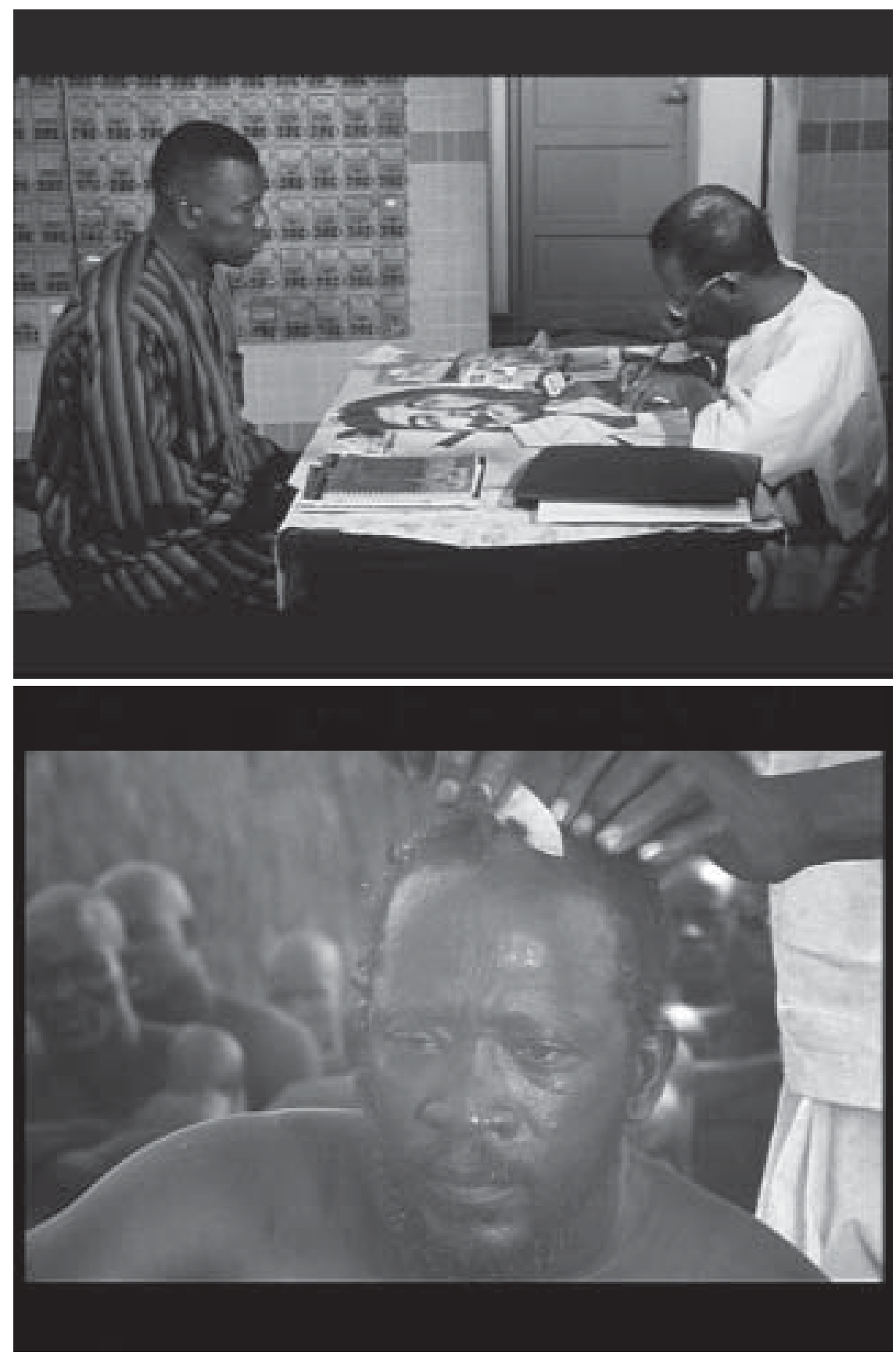

$C 1$. Sembène $O$ usmane écrivain public dans $M$ andabi.

$C 2$. Sembène $O$ usmane ceddo dans $C$ eddo.

Photogrammes publiés avec l'aimable autorisation de M . A lain Sembène. Tous droits réservés. 
et une ethnographie fort complexes de I'A rmée coloniale française, présentant ce corps militaire de la France libre en A frique dans toutes ses contradictions ${ }^{24}$. D'autre part, il s'approprie d'un des symboles les plus populaires du nazisme, le casque SS, le transforme en objet fétiche d'un tirailleur, ex-prisonnier de guerre de Buchenwald, dénommé Pays, qui «n'a plus toute sa raison », pour reprendre l'expression du sergentchef Diatta, rappelant aux officiels militaires français qui questionnaient I'origine des sommes d'argent trouvées dans les baraques des tirailleurs, les exploits et souffrances de ces derniers dans la deuxième gran de guerre à laquelle, eux officiers français de l'A rmée coloniale n'ont pas participé (chapitre 5). Par ce détournement d'un symbole honni, il pointe certes I'horreur nazie qui a détraqué bien des cerveaux, mais aussi plus largement la folie européenn $e^{25}$. En effet, comme en doutait le capitaine Raymond, le seul officier français à comprendre et soutenir la cause des tirailleurs, le film (comme le contentieux qui l'a inspiré) débouchant sur un massacre par l'A rmée coloniale française d'anciens combattants franco-africains à qui la hiérarchie militaire nie le droit à l'égalité leur refusant leurs " arriérés de solde », leur "solde de captivité», et «les indemnités» qui leur sont dus, en plus de leur propre argent de poche confisqué - fait basculer la France libre du général de Gaulle dans le camp de la barbarie, rejoignant l'A llemagne nazie qu'elle a combattue au nom de la liberté.

Bien que le film soit basé sur des événements historiques, reprenant presque, par endroits, le mot à mot des revendications des tirailleurs rapportées en 1983 par un survivant, M. Doudou Diallo, président de la Fédération des A nciens Combattants et Prisonniers de Guerre du

24. À titre d'exemples, citons les contradictions entre l'A rmée française et ses alliés américains de qui elle dépend à divers niveaux ; entre les officiers de la coloniale et le capitaine Raymond de I'A rmée de la France libre; entre les officiers français (coloniaux ou non) et les tirailleurs sénégalais; entre deux anciens combattants français, le capitaine Raymond et le tirailleur, sergentchef Diatta; entre les vétérans tirailleurs rapatriés à Thiaroye et les tirailleurs locaux.

25. Un autre détournement créatif important dans le film qui n'est pas abordé ici, c'est l'usage du «français-tirailleur ». Sur ce point voir l'article en ligne de Cécile Van den A venne (2008) qui soutient en conclusion que «le françaistirailleur fictionnel envahit le film, il devient la norme à l'aune de laquelle les autres variétés vont être mesurées en terme d'écart (et notamment la variété littéraire hypercorrecte du sergent-chef Diatta). Dès lors il perd tout pouvoir de stigmatisation de ses locuteurs. Un renversement s'est opéré ». 
Sénégal ${ }^{26}$, il n'est pas pour autant toujours fidèle aux faits. II y a une part de transformation ou de distorsion de la mémoire historique, en un mot fictionalisation. Sur ce point, Bernard Moitt écrit justement que le film «brosse un tableau de ce que doit avoir été la situation dans un camp bouillonnant de tensions, quelques heures seulement avant l'éclatement de la tragédie.... Sembène le cinéaste [pouvant] se permettre des libertés et atteindre ce que les historiens ne peuvent pas, dans la mesure où il peut rendre l'histoire vivante sur l'écran. » Et il ajoute entre autres : son « regard perspicace de cinéaste » fait du «symbolisme du camp entouré de fil barbelé » «un moteur dramatique» (M oitt $1997:$ 137).

C'est justement la dramatisation sous forme d'un long procès, qui est confrontation/transformation à la manière de Ceddo ou d'É mitaï, qu'impose le medium filmique qui commande une certaine distorsion, du moins une re-création des faits. Par exemple : contrairement au témoignage de Doudou Diallo qui affirme « [qu']après trois sommations, ils [les militaires français] ont ouvert le feu. D'abord les hommes ont cru qu'ils s'agissaient de cartouches à blanc; mais quand ils ont vu leurs camarades tomber, ils ont compris qu'on leur tirait dessus pour de bon ${ }^{27}$, dans le film, il n'y a pas de sommation, I'attaque du camp a eu lieu en pleine nuit, par surprise (voir photogrammes D1-2). L'effet sur les spectateurs est immédiat et beaucoup plus fort. De voir avancer ces chars d'assaut français dans la nuit, se doutant qu'un drame est imminent, le bombardement qui suit d'anciens combattants français désarmés dans leurs lits ne peut que nous bouleverser profondément (chapitre 6). Par ailleurs, dans le film, le général est pris en otage par les tirailleurs. II est enfermé dans une baraque sous la surveillance de Pays qui I'humilie : lui prenant son képi pour lui tendre une chéchia de tirailleur (chapitre 5). C'est là un moment particulièrement fort qui se lit comme une réplique cinglante à l'insulte faite aux tirailleurs rapatriés de leur reprendre uniformes et bottes donnés par l'A rmée américaine pour leur imposer des sandales et uniformes de tirailleurs (chapitre 3). M ais selon Diallo, le général a été seulement «entouré » par les tirailleurs qui «ne

26. Diallo, «L'aube tragique du ler décembre 1944 à Thiaroye (Sénégal) », A frique histoire 7 (1983), 49-51 ; article reproduit dans le dossier du DVD de Camp de Thiaroye fait par la $M$ édiathèque des $3 \mathrm{M}$ ondes.

27. Cette version des faits survenus à Thiaroye à l'aube du $1^{\text {er }}$ décembre 1944 est plus ou moins la même que celle de I'historien M yron Echenberg que cite Bernard Moitt (1997 : 136-137). 

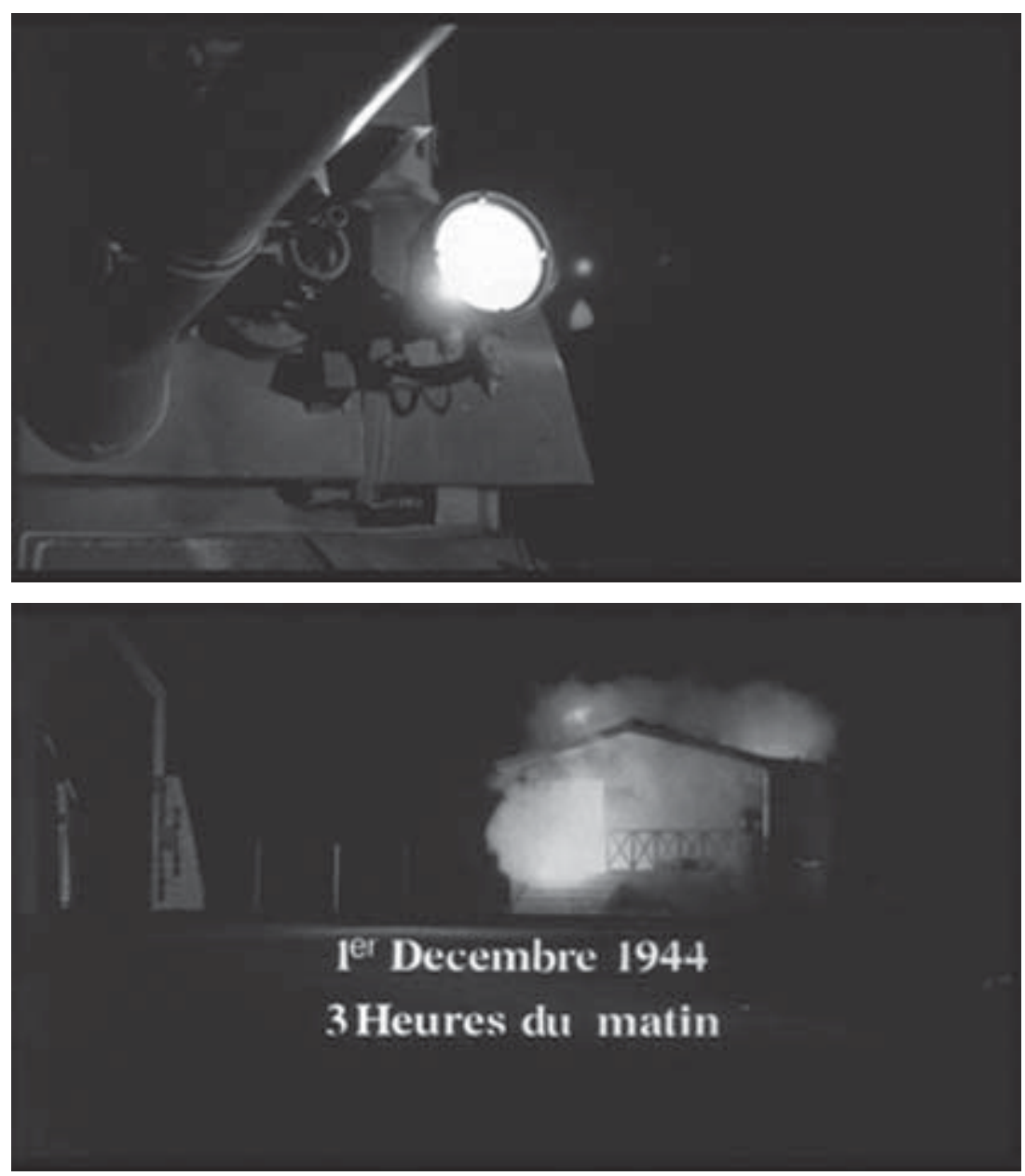

D1-2. C amp de Thiaroye, la dernière scène, le bombardement.

Photogrammes publiés avec I'aimable autorisation de M. A lain Sembène. Tous droits réservés.

[voulaient] pas le laisser partir tant qu'il ne [leur] aurait pas donné l'assurance que tout serait réglé avant [leur] départ. C e qu'il fit » (Diallo 1983 : 51). Dans une lettre au président de la République française en faveur des " prisonniers sénégalais condamnés après les incidents de décembre 1944, au camp de Thiaroye » datée du 16 mai 1947, le député du Sénégal, L. S. Senghor, donne une version plus ambiguë. II écrit : "Sans doute sont-ils [ces tirailleurs] coupables d'acte d'indiscipline en ayant retenu prisonnier un général [je souligne] pour 
appuyer leurs revendications ${ }^{28}$. M ais cette formule hautement rhétorique dans une demande officielle et publique de pardon laisse place à une grande marge d'interprétation qui fait penser que la version de Diallo est plus proche des faits. Senghor, le poète, qui déjà en 1944 faisait l'éloge des tirailleurs assassinés dans «Tyaroye » (H osties noires) réclamant justice, ne tenait-il pas ici, par une concession stratégique à I'histoire officielle, d'amadouer l'autorité française pour obtenir l'essentiel, la libération de ses compatriotes tiraill leurs, anciens prisonniers de guerre comme lui ${ }^{29}$ ? En fait, peu importe, ce geste décisif et irrévérencieux de Pays qui semble avoir ébranlé le général, et le pousser, juste après un plaidoyer d'un tirailleur sur leurs droits ${ }^{30}$, à proposer malicieusement (ce qui n'échappe pas à la perspicacité de son «gardien ») aux tirailleurs de tenir la promesse de les dédommager équitablement comme tout ancien combattant français est une fiction. II permet de construire un momentum dramatique, pour bien marquer une transformation radicale des tirailleurs, et un tournant décisif dans I'histoire africaine. Comme le rappelle, juste avant cette séquence, le capitaine Raymond à ces collègues officiers qui sous-estiment la détermination des tirailleurs: "les petits noirs de type y'a bon banania, messieurs, c'est terminé! » (chapitre 5).

Cette re-création des faits est partie intégrante de la poéthique de Sembène 0 usmane qui implique un passage dialectique obligé de I'historique au fictif (É mitaï, C eddo), du fait divers à I'historique ( La N oire de...), de l'individuel au collectif ( $M$ andabi, G uelwaar, M oolaadé),

28. Voir «Intervention de L. S. Senghor en faveur des condamnés de Thiaroye», une lettre de Léopold Sédar Senghor publiée dans Réveil 215 (12 juin 1947), reproduite dans le dossier du DV D de $\mathrm{C}$ amp de T hiaroye fait par la M édiathèque des $3 \mathrm{M}$ ondes.

29. Dans un article sur des réécritures de I'histoire coloniale par des créateurs africains, Éloïse $A$. Brière fait une toute autre lecture du réseau transtextuel évident entre le film de Sembène 0 usmane et le poème de Senghor. Elle écrit : «On peut concevoir ce film comme faisant partie d'un réseau mémoriel alternatif au discours senghorien, premier à évoquer, dès 1940, les Tirailleurs de la Deuxième Guerre » (Brière 2007 : 144). À mon avis, les rapports entre Sembène Ousmane et Senghor ne sont ni aussi tranchés ni aussi simples. II y aurait toute une recherche à faire sur les échos de l'œuvre senghorienne dans celle de Sembène O usmane, du «G uélowar »/«G uelwaar » au «Tyaroye »| «Thiaroye» que les deux invoquent à la «femme noire» et «les tirailleurs sénégalais » que les deux ont chanté à leur manière en passant par la polémique prétendument « orthographique » qui les a opposé au sujet de C eddo.

30. Sur ce plaidoyer en français-tirailleur, voir I'analyse de Van den Avenne (2008: 119). 
du privé au politique (Xala), de Soi à I'A utre et vice versa. Comme il I'a expliqué, entre autres, à propos d'É mitaï et de C eddo, s'il tient à être authentique et à partir du réel (quotidien ou historique), contrairement au Rouch première manière, avant les ethnofictions, il veut pas dupliquer la réalité et encore moins l'archiver. En fait, il I'utilise comme un matériau primaire pour montrer un procès de transformation, et provoquer une discussion qui dans un second temps peut contribuer à engendrer un éveil des consciences et une vraie transformation sociale. Émitaï offre un bel exemple de sa manière de (re)travailler la mémoire historique ou l'actualité pour les filmer. D'un geste perçu dans la légende comme individuelle, mystique (I'histoire d'A n Sitoë), on passe au récit filmique d'un geste collectif (celui des femmes d'un village) ${ }^{31}$ lié aux traditions ou à l'histoire certes, mais aussi en rupture avec la doxa. La détermination des femmes du village s'inscrit dans une logique de respect et de détournement de deux traditions : celle du rôle central du riz dont elles ont la charge pour leur monde; celle de leur (apparent ou prétendu) mutisme traditionnel dans les affaires de la C ité qu'elles utilisent comme une arme contre l'A rmée coloniale qui n'arrive pas à les faire fléchir même en les gardant prisonnières en plein soleil. Elles font corps comme une seule et même personne dans un geste historique comme le groupe de femmes qui rejoint et soutient Collé $A$ rdo dans son opposition à l'excision dans M oolaadé permet le passage d'un acte individuel (privé) à une action collective publique (politique). II en est de même dans $X$ ala où le problème individuel, sinon intime de l'impuissance sexuelle de $\mathrm{El} \mathrm{H}$ adj devient une affaire publique. Tout Dakar parle de sa ruine jusqu'à son expulsion du groupe des hommes d'affaires qui débouche sur sa harangue contre le néo-colonialisme et la corruption des élites à laquelle fera écho à la fin du film le groupe des paysans qui assaille sa villa pour lui signifier l'origine de son xala et lui rappeler comment il avait spolié des terres familiales pour s'enrichir ${ }^{32}$.

31. Sur le processus d'écriture d'É mitaï, voir G uy H ennebelle 1985 : 27-28, et Paulin Soumanou Vieyra 1972: 123-140, qui donne en détails le contenu du scénario original. Sur A n Sitoë, plus connu comme A line Sitoë Diatta ou A liin Sitoë Diatta avec ses variantes orthographiques A liin Sitooye Diatta ou Jatta, voir W ilmetta J. Toliver-Diallo 2005.

32. Dans une note du 30 septembre 2009 sur une version de ce texte, Samba $G$ adjigo me signalait le caractère nettement historique de la prise de la direction de la Chambre de commerce par des Sénégalais sur laquelle s'ouvre $X$ ala, de même que le caractère autobiographique des reproches faits à $\mathrm{EI} \mathrm{H}$ adj par I'assemblée des mendiants. Ce télescopage d'une histoire collective et d'une histoire personnelle se retrouve aussi dans Camp de T hiaroye notamment. C'est 
Dans un renversement dialectique qui lui est propre, Sembène O usmane fait de cette réunion/confrontation privée, sinon familiale, à la fois une parodie de la mythique crucifixion chrétienne, et une réplique (sinistre) du cercle de palabre africain. En effet, il place El Hadj, à moitié nu, la couronne blanche de la robe de mariée de sa troisième épouse, qui venait de lui signifier le divorce pour impuissance, sur le front, perché sur un tabouret au centre de l'assemblée formée d'un côté de sa famille, de l'autre des déshérités qui ont envahi sa demeure sous la conduite de l'aveugle, majestueusement debout avec son long bâton à la main, commandant de dé-biler sur le condamné. C ette scène, par moment insoutenable, n'est pas sans rappeler la cérémonie du chien des M aîtres fous de Rouch. Par contre, plutôt qu'une catharsis pour les seuls personnages d'un film (comme dans le film de Rouch), elle devient à la manière des grandes tragédies grecques, résolution, et de celle du cinéaste africain, un appel à l'action. Encore une fois, I'appropriation des symboles de l'A utre et des rituels des Siens est dynamique, elle tend à engager au-delà des personnages sur l'écran une communauté qui s'identifie ou peut s'identifier à eux pour une transformation de leur rapport au Monde.

\section{Une contre-ethnographie, qu'est-ce à dire ?}

Le regard sur l'A utre comme le détournement de ses symboles est toujours dialectique, dialogique pour mieux comprendre Soi dans un procès de transformation suite à une crise, qui est prise de conscience de ses rapports aux M ondes, au contact des A utres (d'ici ou d'ailleurs). En effet, contrairement à l'anthropologie classique qui perçoit I'A utre (l'observé) comme coupé de Soi (l'observateur), tout à fait étranger et différent, sinon inégal dans sa pureté de «bon sauvage » ou d'ethnie originelle pour reprendre une expression de Rouch ${ }^{33}$, dans la démarche

là sans doute une forme de la contre-ethnographie et de la poéthique de Sembène O usmane qui mériterait d'être plus amplement étudiée. Par ailleurs, sur l'importance capitale de I'histoire et de I'historiographie dans son œuvre, voir Gadjigo 2004.

33. Suite à une question de $\mathrm{G}$ uy $\mathrm{H}$ ennebelle qui rappelait qu'on accuse le « cinéma ethnographique » d'entretenir « une nostalgie secrète pour le bon sauvage », Rouch répond sans hésitation : "M ais c'est vrai ! C'est vrai ! Rousseau nous a tous marqués. N ous sommes tous à la recherche de notre ethnie originelle » (M artineau et al. 1982: 170). Il est évident que cette quête d'exotisme (ou de I'A utre) qui caractérise toute une ethnographie classique n'a rien à voir avec la démarche de Sembène 0 usmane qui porte sur la crise qu'en gendre une rencontre de Soi avec d'A utres dans un procès de transformation. En ce sens, elle est 
de Sembène O usmane, I'A utre ne peut être perçu (observé) qu'en rapport à Soi, et vice versa. C'est un des premiers fondements de la contre-ethnographie que donnent à lire ses films.

L'histoire de Diouna dans La N oire de ... nous est contée parce qu'elle est devenue bonne à tout faire en France, comme les mésaventures d'I brahima Dieng dans $M$ andabi sont avant tout rapportées pour décrire l'absurde d'une administration sénégalaise calquée sur la française, qui ne tient aucunement compte du pays réel, que Dieng doit affronter pour encaisser un mandat reçu d'un neveu de Paris. El $\mathrm{H}$ adj dans $\mathrm{X}$ ala représente l'impuissance et la corruption d'une classe politique et économique coupée des réalités nationales, à la solde des intérêts étrangers, mais utilisant les traditions nationales à des fins démagogiques. Par contre, Pierre Henri Thioune dans Guelwaar est le symbole d'une dignité et d'une combativité sénégalaises. II refuse l'aide alimentaire étrangère en dénonçant publiquement et vivement les pièges qu'elle recèle pour le pays, mais sa mort, plutôt son assassinat par les autorités, provoque un autre affrontement entre catholiques et musulmans, deux religions étrangères en $A$ frique. Dans $C$ eddo, I'opposition à la pénétration de l'Islam provoque un bouleversement de l'ordre social qui débouche sur l'exécution de l'Iman imposteur par la princesse héritière Dior Yacine qu'il voulait épouser de force. É mitaï et $\mathrm{C}$ amp de Thiaroye relatent des confrontations historiques entre l'armée coloniale française et un village sénégalais d'une part, et des tirailleurs revenant de la deuxième guerre mondiale d'autre part. Le retour des tirailleurs à Thiaroye, comme le village diola d'É mitaï, est filmé parce qu'il offre un moment de confrontation-transformation dans I'histoire de la colonisation française en A frique. II ne s'agit pas d'imponderabilia, autrement dit pour paraphraser $M$ alinowski, ces « habitus quotidiens ordinaires » que les indigènes eux-mêmes expliquent difficilement ( Malinowski 1922: 25), mais d'événements historiques, donc fort singuliers, recréés, transformés, pour agir sur le présent, pour indiquer ou rappeler des voies d'action, de transformation. C'est une position marxiste, du moins militante, qui est tout le contraire d'une démarche ethnographique classique. A utrement dit, bien qu'il parte toujours du réel ou de faits historiques, le cinéma de Sembène Ousmane, qui ne cesse d'insister sur ce point, comme contre ethnographie, ne tente jamais

d'emblée contre-ethnographique. N ous sommes loin de la démarche classique d'un Malinowski qui veut s'éloigner des siens pour mieux comprendre l'A utre que tend encore à enseigner même aujourd'hui une certaine ethnologie; voir Karen 0 'Reilly 2005 : chapitre 1. 
de reproduire une réalité brute à archiver comme dans des documentaires ethnographiques de Rouch ${ }^{34}$. C'est une fiction (fondée certes sur des faits authentiques) d'un moment unique de confrontation avec I'A utre qui engendre une transformation pour l'action, le changement. Sur ce point, Éloïse Brière a raison de relier l'œuvre de Sembène O usmane à la notion de «lieu de mémoire » et d'affirmer, à propos du roman Les Bouts de bois de Dieu, que ce dernier cherche moins à « créer un document historique exact [qu'à offrir] une image d'A fricains oeuvrant consciemment pour leur propre libération » (Brière 2007 : 141). Une telle assertion peut s'appliquer à tous ses films, notamment ceux inspirés de faits historiques, qui sont des appels aux Siens dans leurs langues pour l'action, comme le disent bien les dernières répliques du facteur (en voix off) à Dieng entouré de ses deux femmes (comme dans un cercle de palabre) dans $\mathrm{M}$ andabi : " N ous changerons le pays.... Toi, les femmes, tes enfants. N ous tous» (fin du chapitre 5).

C'est là un second fondement de cette contre-ethnographie, mais étroitement, sinon dialectiquement, lié à un troisième ${ }^{35}$ : la nécessité de l'action collective. En effet, même quand au départ le geste est individuel, il se transforme en mouvement social, et n'aboutit que dans I'action collective. L'individu se définissant toujours en rapport à un groupe qui prend sens (notamment pour les spectateurs) à travers des individualités représentatives (porte-parole ou non). Pour réussir, sinon survivre, l'individu doit rejoindre un groupe ou être rejoint par un groupe, non le groupe - l'ensemble social étant toujours fragmenté, fissuré dans les films qui donnent à voir des stratégies d'appartenance ou d'identification, des déplacements d'un groupe à l'autre : Dior Yacine de retour de captivité qui rejoint le camp des ceddos (et est rejointe par eux) dans un renversement narratif qui aboutit à un climax, I'exécution de I'Iman. Ce sont ces perturbations ou renversements qui font du récit filmique un objet (esthétique) captivant. Sembène O usmane les utilise à dessein. Par exemple, Diouana se rappropriant du masque qu'elle avait offert à sa patronne, par ce geste inattendu rejoint son groupe qui, à son tour, se solidarise autour de sa mort pour

34. Selon Faye Ginsburg (1996: 835), Rouch a réalisé plus de 120 films, aussi importe-t-il de rappeler que ce commentaire porte avant tout sur les documentai res cités ici, non sur l'ensemble de sa production qui est difficilement accessible, et surtout comprend au moins de grands types de films, des documentaires proprement dits, et des docu-fictions ou ethnofictions.

35. Ce classement numérique n'implique aucunement une hiérarchisation. II est donné pour faciliter la lecture. 
signifier à M onsieur leur refus de vendre leur âme. En effet, sa mère à Dakar, comme elle avant de se suicider à A ntibes, refuse l'argent de Monsieur, et son petit frère ramasse le masque pour poursuivre $M$ onsieur, comme une réappropriation symbolique de l'ethnographie africaine.

$M$ on hypothèse de présenter le cinéma de Sembène 0 usmane comme ayant partie liée à ethnographie : (double) contre-ethnographie, comme on parle de contre-discours - ou plus précisément, ce qui n'est qu'une définition minimale : une ethnographie de Soi pour Soi dans ses divers rapports au M onde, sinon ses confrontations avec d'autres ( $d^{\prime}$ ici ou d'ailleurs), dans sa ou ses langue(s) indigène(s) selon ses propres formes d'expression - va à l'encontre de toute une tradition critique du cinéma africain. En effet, généralement ses films sont qualifiés de réalistes, historiques, politiques, militants, loin du cinéma ethnographique d'avant les Indépendances perçu comme exotique, colonialiste. Certes, comme je viens de le montrer également plus haut, son cinéma s'inscrit dans ces divers courants, mais il n'est pas que cela. II est aussi autre autrement.

En fait, se plaçant dans une perspective de redéfinition de l'image filmique africaine, Sembène Ousmane ne pouvait éviter de revisiter (revoir et réévaluer) ces stéréotypes et mythes coloniaux, sinon colonialistes d'une certaine ethnographie, et de son cinéma en particulier, pour créer de nouvelles images d'un continent en mouvement. C'est le sens même de sa question à Rouch en 1965 qu'il convient de rappeler encore une fois: "Est-ce que, Iorsqu'il y aura beaucoup de cinéastes africains, les cinéastes européens, toi par exemple, comptent continuer à faire des films sur l'A frique? » (Cervoni 1982 : 77), et jusqu'à un certain point, le moteur conscient ou non de sa démarche cinématographique qui fait parfois subtilement écho à Rouch comme dans C amp de Thiaroye qui reprend et le symbole nazi (le casque de Pays) et le coq gaulois (la pancarte du « Coq hardi », le bordel où le sergent-chef Diatta se fait virer parce que $A$ fricain) qui se retrouvent dans $M$ ammy $W$ ater sur des voiles de pêcheurs. O $\mathrm{n}$ peut aussi voir l'insistance sur le rituel des repas dans $M$ andabi, ou même l'égorgement par le marabout du mouton dans $\mathrm{C}$ amp de $\mathrm{T}$ hiaroye, comme réponse à la cérémonie des chiens dans Les M aîtres fous (1954/ 1957). À un autre niveau, soulignons que des remarques de Rouch sur É mitaï, reprochant à Sembène Ousmane de n'avoir pas rappelé que «[ces] gens [les tirailleurs] ont libéré la France malgré les Français; il y avait très peu de Français, tous les types venaient d'A frique. Ça pouvait être dit! » ( $H$ affner 1985 : 93), semblent trouver écho dans C amp de Thiaroye 
quand Diatta rappelle aux officiers français les prouesses des tirailleurs dans la dernière grande guerre à leur place (chapitre 5). Par contre, il y a un tout autre aspect de ce dialogue cinématographique franco-africain qui semble moins évident, mais tout aussi important : celui d'une certaine influence de Sembène O usmane sur le cinéma de Rouch. En d'autres termes, jusqu'à quel point les films de Rouch après la " confrontation » de 1965 font-ils écho aux propos, sinon aux films de Sembène O usmane? Par exemple, le Paris de Petit à Petit (1970) ne serait-il pas une contre-réplique de celui des A fricains de M andabi (1968) ? ou encore $P$ etit à Petit une réponse à $L$ a $N$ oire de... ? Q u'importe les réponses, il reste que $\mathrm{R}$ ouch a été porté du moins une fois à comparer publiquement et candidement sa démarche cinématographique avec celle du Sénégalais. À propos de Mandabi, il dit en 1985 : "J'avais dit à Sembène : j'aurais montré dans un de mes films ton gars en train de manger et de roter comme ça, on m'aurait traité de salopard! Q ui regarde I'A fricain comme un insecte! Toi, tu peux le faire, merci ! » (Haffner 1985 : 91). II semble donc évident pour lui que du point de vue de la réception du moins, Sembène Ousmane, étant africain, jouit d'un avantage, celui de pouvoir parler des siens sans se faire accuser de tous les noms, et bien sûr de faire le tour de son jardin (ethnologique) sans retenu ou presque. A vec un enthousiasme admirateur, il souligne : "Traiter du problème de l'impuissance sexuelle en A frique, il faut être gonflé comme Sembène pour le faire! C'est pourquoi un iconoclaste comme lui (et dans $C$ eddo n'en parlons pas) aurait dû faire quelque chose dans É mitai sur les héros! X ala c'est drôle, on retrouve le $M$ andat, et il dénonce tout, avec un courage sans borne ! Plus que la bureaucratie, la bourgeoisie profiteuse, et il le fait avec un érotisme extraordinaire! » (H affner 1985: 93).

A ussi, force est de reconnaître que Sembène Ousmane reprend systématiquement de nombreux objets ou pratiques hautement canoniques ou symboliques des descriptions ou discours ethnographiques sur l'A frique: de la palabre, confrontation ou confortation, qui se retrouve, sous une forme ou une autre, dans tous les films au griot, chanteur ou conteur, dont la voix hante toutes les bandes sonores. Sur ce point, en conclusion de son mémoire sur les cinémas de Rouch et Sembène O usmane, $C$ harlotte $M$ eyer écrit : « Les résultats de l'analyse des films Borom sarret et La N oire de... témoignent bien de la volonté de Sembène d' «africaniser» son œuvre cinématographique. L'esthétique de ces films se manifeste par l'insertion de plusieurs éléments 
de la tradition orale africaine.... O n constate en surplus l'importance des objets traditionnels africains significatifs, sinon symboliques » (M eyer $2005: 120-121)^{36}$. C ette réappropriation esthétique manifeste de formes d'expression perçues comme typiquement africaines est des plus achevées et les plus fortes dans $C$ eddo et $M$ oolaadé par l'usage systémique des griots qui doublent et encadrent en même temps par leur narration le récit ou le dialogue filmiques. Elle se manifeste également par les danses rituelles ou non qui expriment les joies ou les peines d'un individu (Diouana dans La N oire de... sur les monuments aux morts après qu'elle ait été rassurée d'aller en France avec ses patrons) ou d'un groupe (la danse des villageois enterrant leur chef dans É mitaï, celle des tirailleurs après les fausses promesses du général français à la fin de Camp de Thiaroye).

En effet, d'un film à l'autre, de la place capitale du masque dans La $\mathrm{N}$ oire de..., en passant par le cérémonial des repas dans $M$ andabi, jusqu'aux tambours parlants de M oolaadé qui, au début du film, par personnage-interprète interposé ${ }^{37}$ font pour l'auditoire (non initié au langage des tam-tams) le récit de la crise qui frappe la société - une rupture dans l'équilibre social qui mènera à une transformation (profonde) : six filles qui refusent l'excision sont en fuite - , Sembène O usmane construit une poéthique qui récrit le discours ethnographique.

Les exemples sont multiples de ce détournement/recentrement pour Soi et sur Soi qui n'est plus objet figé d'un discours exogène, mais sujet d'un procès de mises en scène de rapports au monde divers, complexes avec des individualités marquées et des groupes non homogènes. Q u'il

36. A u passage, il importe de souligner que suivant en ce sens une tradition critique bien instituée, $M$ eyer ne voit point le cinéma de Sembène 0 usmane, comme je le soutiens ici, un cinéma ayant partie liée à l'ethnographique. Par ailleurs, les exemples qu'elle donne comme caractéristiques de la «tradition orale africaine » ( «la structure linéaire des récits, une certaine dialectique entre le protagoniste et l'antagoniste, le caractère de l'escroc ainsi que la quête ou l'aventure ») sont loin d'être exclusivement ou même proprement africains.

37. Il importe de noter que c'est la première épouse du mari de Collé qui demande à son mari d'interpréter le message des tam-tams comme si elle ne savait pas déjà, du moins intuitivement, de quoi il en retournait. Dans Émitaï, il y a une scène plus ou moins similaire, mais il semble évident que l'officier français qui demande au sergent tirailleur de lui interpréter les tam-tams annonçant la nomination du nouveau chef ne se doute point du contenu de ce message typiquement africain. Ici, il est manifeste que le recours à l'interprète est aussi un rappel de l'ethnologue questionnant son informateur (chapitre 3). 
s'agisse des couteaux des exciseuses jetés au feu où brûlent les radios portatifs devant la mosquée dans M oolaadé ou de la longue suite de visites infructueuses de El $\mathrm{H}$ adj aux marabouts et féticheurs à travers le pays dans $X$ ala - dont le titre même, impuissance temporaire causée par un sort, relève des croyances populaires ${ }^{38}$ est tout un programme ethnographique - , Sembène 0 usmane fait toujours un usage dynamique, dialogique, dialectique des traditions (quatrième fondement d'une contre-ethnographie) : rejetant celles jugées désuètes, prônant celles jugées dynamiques, progressives. Un bel exemple de cette dialectique est le combat de Collé contre excision au nom du droit d'asile (le moolaadé) qu'elle ne saurait refuser aux jeunes filles qui lui demandent protection dans M oolaadé. Toujours dans cette logique de remise en question de traditions perçues comme inacceptables ou dégradantes, se référant à sa propre expérience, Collé A rdo, face à l'assemblée des hommes, rappelle la différence fondamentale entre le couteau qui donne espoir et vie (le bistouri de sa césarienne) et le couteau qui sème angoisse et mort (celui des exciseuses) au nom d'une tradition qui n'est pas inscrite dans la loi islamique comme l'a annoncé le grand Iman à la radio (cette voix qui informe et ouvre sur le monde extérieur). II appert donc que tout apport étranger n'est pas à rejeter, comme toute tradition ancestrale peut être réévaluée ou évoluée. C'est le constat que faisait déjà dès 1977, à partir d'une lecture d'É mitaï, Bernard N ave qui écrivait

\begin{abstract}
A insi, si à première vue, il s'agit d'un film à la gloire de la femme dans sa détermination sans faille, É mitaï développe un propos plus divers et plus complet à la fois. Ce sont les femmes qui tout au long de la lutte ont l'attitude la plus résolue et unanime face à l'armée venue chercher le riz. Elles montrent aux hommes et particulièrement aux chefs absorbés dans leurs palabres la voie de la résistance. $M$ ais le film ne saurait se résoudre à cette opposition dans la mesure où le sens de cette lutte est de montrer comment certaines contradictions sont amenées à se résoudre dans la lutte. A insi le thème religieux prend ici
\end{abstract}

38. A vec l'excision (au centre du M oolaadé), les croyances traditionnelles dites superstitieuses sont les champs privilégiés des discours occidentaux ethnographiques ou non sur I'A frique. Oubliant leur propres marquages/ marchandages des corps, de la vogue des tatouages à la chirurgie plastique en passant par l'industrie de l'augmentation du volume des organes sexuels, le $\mathrm{N}$ ord en général ne cesse de gloser sur ces pratiques africaines. Sembène 0 usmane les rejette, certes, mais c'est de manière respectueuse dans un souci de transformation sociale et non d'une hantise du refus des pratiques de l'A utre perçues comme sauvages, primitives. 
une place plus importante que dans les autres films de Sembene O usmane, dans la mesure où il ne se contente pas de présenter la religion seulement comme aliénante, mais d'en analyser le rôle de façon dialectique, à la lumière de la place qu'elle occupe et du rôle qu'elle est amenée à jouer face à une réalité historique. A vec É mitaï, on peut dire qu'il y a une remise en cause de dieux, une interrogation sur leur existence même, face à leur mutisme dans une situation qui remet en question les structures du groupe social. Sembene O usmane nous fait sortir d'une vision figée de la religion africaine où les croyances et les rites seraient des choses immuables et indépendantes du contexte dans lequel elles existent. II nous les présente comme un donné de la tradition populaire, susceptibles d'évoluer et d'être remises en cause par la vie ( $\mathrm{N}$ ave 1977 : 35-36).

L'évocation des traditions (rituel, coutume, savoir-faire) n'est jamais gratuite, elle s'inscrit dans une trame narrative, elle concourt à un dénouement : une transformation d'une situation initiale vers une finale suite à une perturbation dans l'ordre social ou les rapports entre différents acteurs sociaux. Elle répond à un besoin poéthique, donc esthétique et éthique. Plus globalement, on peut dire que Sembène O usmane ne recourt aux formes dites traditionnelles (pâtures de l'ethnographie ou de l'anthropologie coloniale ou postcoloniale) que comme manière non figée en procès de confrontation/transformation (qui fait suite à une crise) dont il reconnaît être partie prenante par sa présence même discrète comme acteur dans ses films. Pour mémoire, rappelons quelques personnages qu'il interprète qui sont loin, par exemple, de l'omniprésence d'un Jean Rouch comme narrateurcommentateur de ses films : maître d'école populaire dans La N oire de... (chapitre 18), écrivain public dans $M$ andabi (chapitre 2), ceddo rebaptisé parmi les ceddos lors de la grande conversion forcée sur la place du village dans Ceddo (chapitre 4), le tirailleur dans É mitaï qui questionne son sergent sur l'étrangeté du remplacement du maréchal Pétain par le général de Gaulle à la tête de l'A rmée française (chapitre 3).

De même, il ne reprend des stéréotypes sur la France et les Français, ou plus largement des icônes ou symboles européens ou occidentaux - tours d'habitation en France dans La N oire de..., le poster de De Gaulle et la discussion qu'elle entraîne dans É mitaï, la radio et la télé dans M oolaadé, la Tour Eiffel et les balayeurs noirs à Paris dans M andabi, la chanson «Q ue reste-t-il de nos amours» de Charles Trenet dans la scène du bordel de Camp de Thiaroye, faisant du coup un clin d'œil aux 
Baisers volés de Truffaut ${ }^{39}$, la riviera française et le paquebot de croisière dans La N oire de...., la grande messe catholique de Ceddo - que pour les déconstruire par un regard africain, irrévérencieusement indigène, porté sur eux. A ussi, le traditionnel sujet/observateur jamais observé - du moins se croyant jamais observé, ou ne relatant que très rarement, sinon jamais dans son discours (récit ou description ethnographique qui tente de rapporter le particulièrement typique d'une société perçue comme homogène et figée dans ses traditions), les questions de l'autre/ indigène sur lui/étranger et encore moins la rencontre de ces deux mondes et les conséquences (voir Laplantine et Saillant 2005 : 21-22) - se retrouve dans ses films objet observé. Pire ou mieux encore, il est jugé non dans une langue dominante du Nord mais celle des dominés du Sud, Sembène $O$ usmane à partir de $M$ andabi, filmant prioritairement en langues africaines. Sur ce point, la belle harangue de Pierre Henri Thioune dit Guelwaar, dans le film homonyme, contre l'aide étrangère qui piétine la dignité des $\mathrm{A}$ fricains, à laquelle fait écho les propos de sa veuve appuyant des jeunes gens qui, refusant de vivre et de grandir en mendiant, versent sur la route les sacs de nourriture états-unienne reçue des autorités soupçonnées d'avoir assassiné son mari qu'elle allait inhumer, est exemplaire. O n n'est loin de la neutralité et de l'ex-centricité de l'ethnologie ou de l'anthropologie ${ }^{40}$ classique qui, dans un rapport

39. Il y a plusieurs références explicites au cinéma ou à des cinéastes dans les films de Sembène O usmane, voir entre autres : le petit garçon jouant à Zorro dans La $\mathrm{N}$ oire de... (chapitre 12) ; les affiches entre autres de Charlie Chaplin et du $\mathrm{M}$ andat dans $\mathrm{X}$ ala (chapitre 3 ) ; I'affiche du C orbeau de $\mathrm{H}$ enri-G eorges $\mathrm{Cl}$ louzot dans C amp de T hiaroye (chapitre 2) - voir photogrammes E1-2. La présence de cette dernière affiche, comme toutes les autres, est motivée. Elle renvoie fort probablement à une certaine collaboration française avec le fascisme, notamment dans les colonies: Le Corbeau étant I'histoire d'une série de dénonciations (par lettres anonymes). II convient aussi de rappeler qu'à cause de ce film produit par une compagnie allemande établie en France, Continental Films, Clouzot a été accusé d'être un collaborateur. C'est justement le reproche du sergent-chef Diatta à l'A rmée coloniale française en A frique, lui qui, quelques jours avant avait vu l'annonce du film sur un trottoir de Dakar, juste avant de se faire virer d'un bordel, parce que «bougnoule ». En fait, on pourrait même extrapoler et dire avec Paulin Soumanou Vieyra - qui cite à titre d'exemple : « le chapelet » dans Borom Sarret; le «mandat» dans le film éponyme; le « masque » dans La N oire de... ; le « pantalon » dans Taw - que les objets dans les films de Sembène O usmane, peu importe leur nature, « sont significatifs quand ils ne sont pas symboliques» (Vieyra 1972 : 155).

40. La similitude ici établie entre ethnologie et anthropologie, bien que contestée ou contestable, est assez instituée, du moins dans l'espace francophone. Elle se retrouve sous la plume de plusieurs auteurs fort représentatifs de la profession de Michel Izard qui soutient : «l'ethnographie intervient ... dans la première 

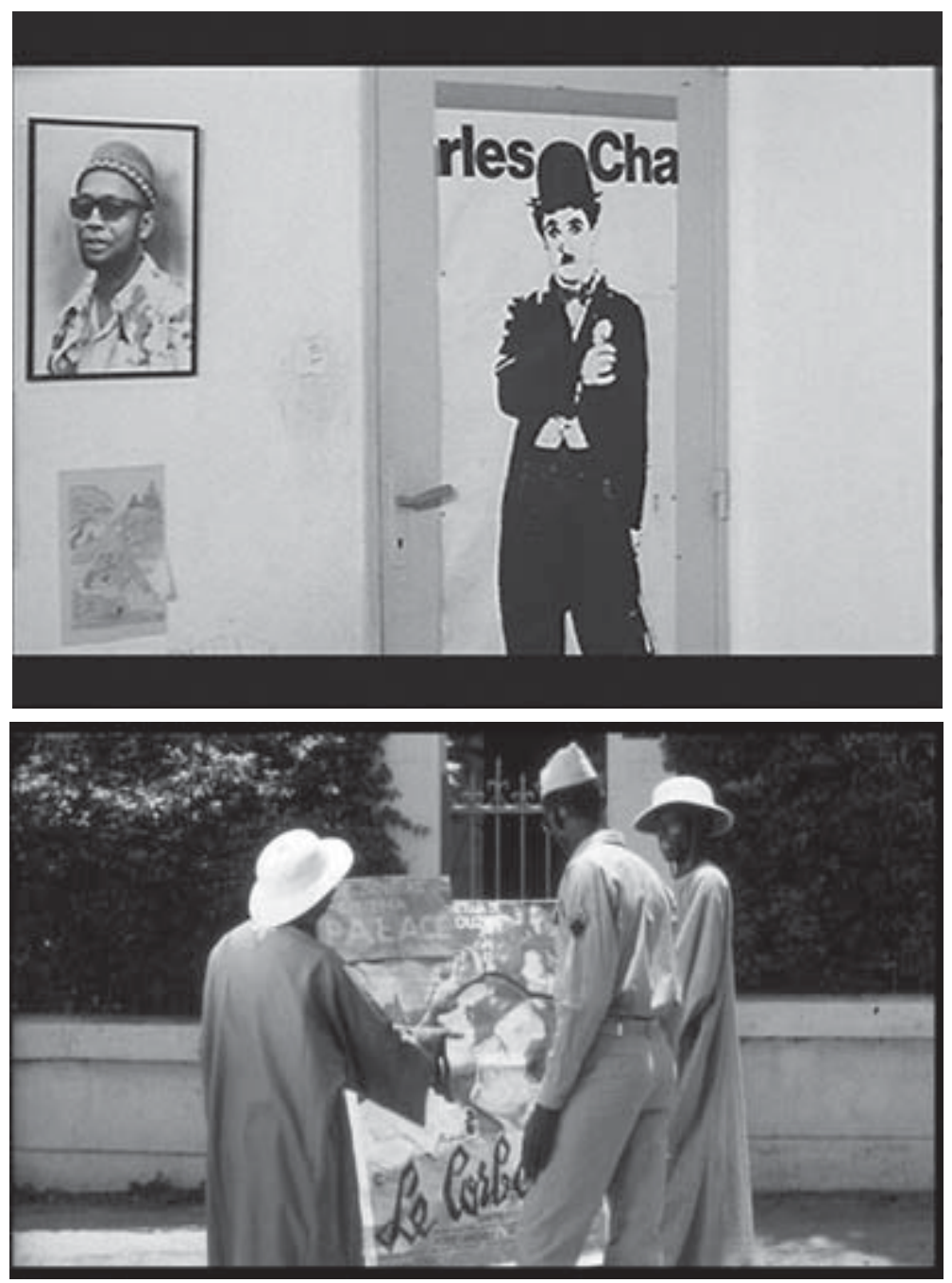

E1. Xala, A ffiche de Chaplin

E2. C amp de Thiaroye, affiche du Corbeau.

Photogrammes publiés avec I'aimable autorisation de M. A lain Sembène.Tous droits réservés.

étape du travail anthropologique » à François Laplantine et Francine Saillant qui écrivent « I'anthropologie ... est d'abord ethnographie» (voir Izard 2007 : 470 ; Laplantine et Saillant 2005 : 21). Par ailleurs, il importe de rappeler que notre propos concerne avant tout l'ethnologie/ethnographie moderne dite classique, celle instituée entre autres dans la foulée des travaux d'un M alinowski qui fait du «terrain », autrement dit le séjour prolongé dans la société autre à décrire, une étape incontournable de la recherche (voir Izard 2007 et 0 'Reilly 2005 : chapitre 1). 
inégal, postule une enquête qualitative sur un autre différent, du moins perçu comme tel, non pour le groupe investigué, mais celui de l'investigateur dans sa langue ou celle de ses commanditaires. M algré I'intégration de bribes de langues indigènes, I'anthropologie partagée de Rouch est présentée en français comme la « reverse anthropology » de $M$ anthia Diawara est en anglais $s^{41}$. En ce seul sens, la contre-anthropologie de Sembène 0 usmane est déjà radicalement différente. À l'encontre de ces tentatives importantes antérieures ou postérieures d'une ethnographie autre, elle se fait d'abord en langues non européennes (notamment celles réputées sans savoir), même quand les dialogues, comme dans C amp de Thiaroye, sont massivement en "françaistirailleur ». Ce cinéma fictionnel, aucunement documentaire, touchant à la fois divers acteurs de la rencontre (dominants et dominés, investigateurs et investigués), se fait avec et pour les dominés dans leur langue (généralement des acteurs non professionnels), selon leur mode d'expression, leur sensibilité et leur capacité de compréhension. A ussi, compte tenu des défis linguistiques propres au sous-continent africain avec ses 2000 langues indigènes, et de la volonté du cinéaste sénégalais de tourner pour toute I'A frique, cette œuvre est plutôt différente des expériences cinématographiques militantes latino-américaines des années 1960-1970 comme celles de Jorge Sanjinés ou Fernando Solanas, par exemple, bien qu'elles se recoupent par endroits ${ }^{42}$.

\section{Intentions poïétiques et réalités esthésiques : des limites de la voie filmique}

Le lecteur attentif l'a sûrement perçu, I'analyse qui précède se construit principalement sur deux ordres de discours, I'un poïétique, l'autre esthésique (au sens que donnent à ces termes Jean Molino 1988) : des propos des cinéastes sur leurs œuvres; des analyses de leurs productions. Dans le cas des films de Sembène O usmane qui nous intéressent au premier chef, cette critique est généralement exogène, du moins se fait hors du continent africain (même quand elle est d'A fricains de naissance ou d'adoption), comme les premières des films qui ont lieu général ement à l'étranger dans le cadre de festivals internationaux. Un film comme C eddo a même été interdit au Sénégal pendant des années ${ }^{43}$, L'Empire

41. Voir M anthia Diawara, Rouch in Reverse [vidéo] (San Francisco: California N ewsreel, 1995).

42. Pour un regard de première main sur ces cinémas latino-américains, voir entre autres: Fernando Solanas 1975 ; J Jean Jonassaint 1978.

43. Selon Mamadou Diouf, dans une note fort judicieuse sur l'interdiction du film 
Songhaï ( son premier et seul film entièrement produit par un état africain, le Mali) n'a jamais été diffusé, des doutes mêmes subsistent sur son existence ${ }^{44}$. Par ailleurs, les sous-titrages des films sont en langues européennes: français et anglais principalement, donc nullement disponible pour l'A fricain qui ne maîtrise ni l'une des trois ou quatre langues indigènes de ses films, ni le français ou l'anglais. D'autre part, les droits de diffusion sont détenus par des firmes étrangères (angloaméricaine et française) soit, jusqu'à sa faillite récente, $\mathrm{N}$ ew Yorker Films pour les U SA, la M édiathèque des Trois $M$ ondes pour la France, ses deux plus gros marchés institutionnels du moins. Pourtant le cinéaste sénégalais prétend vouloir parler à son peuple qui, pour lui, déborde les frontières de son pays pour englober au moins toute l'A frique au sud du Sahara. Comment y parvient-il ? T hat is the question! Selon Charlotte $M$ eyer, par exemple, reprenant des données qui remontent aux années 1960, la réponse est plutôt négative. Elle conclut son mémoire, affirmant

\begin{abstract}
... II veut faire un cinéma pour les A fricains - hors de toute influence européenne - qui montre une image réelle de l'A frique, qui évoque des sujets africains contemporains et qui reflète, par son esthétique cinématographique africaine inspirée de la narration traditionnelle, les spécificités culturelles de I'A frique.... N éanmoins, il importe de noter que la réalité du cinéma d'A frique noire est tout autre : il n'a pas d'audience hors d'une certaine clientèle (qui est souvent européenne), il n'est pas financé par l'A frique(comme l'aurait voulu Sembène) et, à cause des problèmes de distribution, les films ne sont montrés que rarement en A frique même. N otons aussi la rareté des salles (en 1963, une demie-place pour 100 habitants) et leur faible fréquentation par la population. En bref, malgré les efforts de Sembène, la plupart des films projetés sur les écrans africains restent des films étrangers ( $M$ eyer 2005: 120).
\end{abstract}

De prime abord, ma propre expérience nord-américaine avec des étudiants africains (de familles riches ou non) me pousse à pencher dans la même direction. En effet, sauf rares exceptions, ces jeunes africains ignorent même le nom Sembène O usmane ou O usmane Sembène qui, lui-même, rappelait à $C$ annes en 2005 que le "cinéma en $A$ frique connaît de graves problèmes. De production : il y a peu de films, mais surtout de diffusion : personne n'y voit nos propres films. Le

au Sénégal, ce n'est que cinq ans après sa sortie en 1981, suite à la démission du président Senghor, que Ceddo a pu être présenté au public sénégalais - voir Diouf (1997 : 20, note 2).

44. Voir entre autres Pierre $H$ affner qui dit : « cet Empire Songhaï, ...on ne sait pas très bien s'il est achevé... » (H affner 1985 : 88). 
manque de distribution des films africains sur notre propre continent est un grave handicap » (Sembène Ousmane 2007 : 198). II n'est donc pas étonnant que les étudiants africains (ou d'origine africaine) à l'étranger soient très peu intéressés à leur cinéma en général, qu'on les voit rarement, sinon jamais de leur propre chef, dans les rencontres sur cette production. Toujours sur un autre plan proprement africain, la comédienne Thérèse $M$ 'bissine Diop (aussi connue sous le nom de $M$ 'bissine Thérèse Diop qui apparaît au générique de La $N$ oire de... ), rappelant avec une certaine amertume, quarante ans plus tard, I'ostracisme qu'elle a subi tant de sa famille immédiate, notamment sa mère, que de parents et voisins d'avoir joué dans ce film, donne à penser qu'une bonne part de la population sénégalaise, du moins dans un premier temps, n'a pas vu d'un bon œil l'émergence d'un cinéma sénégalais fait par des Sénégalais (voir Coulpier et Senthiles 2008) ${ }^{45}$.

Jean-Pierre Bekolo dans son film Le Complot d'A ristote/ A ristotle's Plot (1996) semble donner une réponse plus ou moins similaire dans sa fable d'un cinéaste africain en A frique, Essemba Tourneur, dont le prénom est l'anagramme de Sembène, et un nom de famille, Tourneur, rappelle le retournement opéré par O usmane Sembène pour se donner un nom d'auteur. D'autre part, le synopsis du film diffusé sur le site de «France Diplomatie », qui est fort probablement de Bekolo, condense une histoire qui pourrait être celle du regretté aîné des anciens. En effet, cette fable - un « cinéaste maudit chassé d'Europe [qui] rentre au pays [pour découvrir] avec stupeur que la vieille salle de cinéma est littéralement occupée par une bande de jeunes malfrats dirigée par un africain surnommé "Cinéma" qui consomme à longueur de vie des films américains» - n'est pas sans rappeler le retour de l'écrivain Sembène Ousmane au Sénégal pour constater qu'il était inconnu chez lui. Par ailleurs, n'est-ce pas aussi son combat que celui d'Essemba Tourneur qui « décide de récupérer les lieux pour y projeter des films africains »? Et I'ultime victoire (à la Pyrrhus sans doute) de ce dernier

45. Par ailleurs, comme me le signalait Samba Gadjigo dans un courriel en date du 30 septembre 2009, il importe de noter qu'une autre lecture possible soit que le véritable problème rencontré par Thérèse $M$ 'bissine Diop, relève de « l'ostracisme contre le métier de comédien qui est le plus souvent associé aux castes dites inférieures. » 
dont les «villageois ... adorent » les films africains que leur projette la gang de "Cinéma », "la mort dans l'âme » ${ }^{46}$, renvoie jusqu'à un certain point aux tournées de Sembène 0 usmane avec ses films à travers le Sénégal. Par ailleurs, sans le dire explicitement, dans un entretien avec Olivier Barlet, Bekolo laisse entendre que son film se fait bien en référence au Sénégalais, sinon contre lui. En effet, à la question, «Pourquoi avoir choisi A ristote?», il répond longuement :

Q uand on m'a demandé de faire un film sur le cinéma africain pour le centenaire du cinéma, c'était déjà contradictoire. De plus, les autres réal isateurs étaient des grands, comme Scorcese, Bertolucci, Godard, Frears... et moi, je n'étais personne.... Je me suis donc demandé ce qu'était le cinéma moderne : raconter des histoires! Dans les stages de scénario, la première personne citée est A ristote : « une bonne histoire doit susciter la crainte et la pitié ». J'ai donc relu La Poétique, base de tous les récits occidentaux. C'est là que se fait la différence avec I'A frique. L'humour et la dérision s'avèrent une force culturelle intéressante pour le cinéma. La comédie affirme Dieu en soi-même, une capacité de résolution interne des problèmes, al ors que la tragédie, comme la religion chrétienne, place Dieu à l'extérieur de l'individu. En A frique, les gens ont Dieu en eux-mêmes. $M$ ais lorsque Sembène 0 usmane filme l'A frique, il la situe dans la tragédie ! C ette génération a voulu faire ce qu'on lui avait appris. Bien sûr, on utilise un langage mais l'outil cinéma permet d'autres possibilités. C'est le sujet du film ; il ne donne pas de recettes, il ne dit pas comment il faut faire : il ne fait qu'en parler.

Puis en réponse à une seconde question, il ajoute :

...je m'identifie à très peu de films africains! Ce qui m'intéresserait, ce serait une certaine attitude face au monde. Je trouve grave de voir à $\mathrm{C}$ annes des films africains qui fuient la réal ité africaine actuelle; ce sont des films aseptisés. $0 \mathrm{n}$ ne peut prétendre exprimer quoi que ce soit si l'on a pas pensé notre relation au monde moderne [je souligne] ${ }^{47}$.

Les commentaires de Bekolo nous ramènent à une question fondamentale qui se pose peu ouvertement : «Q u'est ce qu'un film

46. Voir France Diplomatie, Le C omplot d'A ristote de Jean-Pierre Bekolo à http:// www.diplomatie.gouv.fr/fr/actions-france_830/cinema_886/aidesproduction_5622/films-aides_5623/films-aides-par-fonds̄-sud_5624/ cameroun_71̄13/complot-aristote_7178/index.html.

47. Voir Entretien d'Olivier Barlet avec Jean-Pierre Bekolo ( $C$ ameroun) à propos du Complot d'A ristote, A fricultures (juin 1997) en ligne à http:// www. africultures. com/php/index. php?nav $=$ article\& no $=2477$. 
africain ? » Je l'ai abordée à l'hiver 2009 dans un séminaire avec trois étudiants nord-américains, deux Européennes (dont une Française) et une A fricaine (Sénégambienne), malgré les limites de l'échantillon, les résultats sont assez évidents et significatifs. L'A frique urbaine ou urbanisée des films comme M adame Brouette de Moussa Sene A bsa (2004) ou Q uartier M ozart de Bekolo (1992) est perçue moins africaine, sinon non africaine, comme celle coloniale et militarisée de Camp de Thiaroye, par exemple. Par ailleurs, pour les étudiants de tous les films du questionnaire, M oolaadé est le plus africain (abordant, selon eux, 5 sur 6 des problèmes distinctement africains) ; puis viennent dans l'ordre décroissant $M$ andabi (dont les principaux personnages sont authentiquement africains) et $M$ adame Brouette. $Q$ uant à $Q$ uartier $M$ ozart, ils l'ont perçu à la limite peu africain, comme le sergent-chef Diatta de $\mathrm{C}$ amp de Thiaroye (qui écoute la musique classique, le jazz, lit des auteurs français), pour quatre d'entre eux, n'est presque plus africain. De la discussion, il semblait se dégager une vision plutôt stéréotypée de I'A frique - rurale ou illétrée, sinon sauvage, aucunement urbanisée ou modernisée. Est-ce là ce que Bekolo tend à dénoncer ou ne fait-il qu'exprimer un conflit générationnel, sinon national ou de classe ? La petite bourgeoisie africaine - du moins un segment de cette classe urbanisée, ceux d'après les Indépendances, contrairement aux ruraux et à la génération des Indépendances - ne se retrouve pas, à tort ou à raison, dans ces images du pays profond ou d'antan, plutôt «folkloriques » ou «non modernes» pour eux. A u-delà de l'intérêt de villageois africains ou d'étudiants étrangers pour le cinéma du regretté aînés des anciens, il faut reconnaître les réussites de son entreprise artistique. De mobiliser tout un village sénégalais pour le tournage d'É mitaï, ou burkinabé pour celui de M oolaadé, de réunir des comédiens de toute l'A frique de I'O uest pour C amp de Thiaroye, ce sont des succès incontestables pour l'émergence d'une cinématographie africaine populaire (au-delà des frontières nationales, ethniques ou linguistiques). S'il y a des ratages sur le plan de la réception nationale ou pan-africaine, malgré la Fespaco et $C$ arthage, il reste que sur le plan régional et international, son œuvre a trouvé une audience exceptionnelle. En effet, qu'un film d'un jeune cinéaste africain (commandité par le British Film Institute pour le centenaire du cinéma) prenne pour référence cette production pour parler de cinéma est bien signe de la fortune 
extraordinaire de Sembène O usmane qui a su aussi trouver une place, à côté des plus grands cinéastes encore vivants, dans L es L eçons de cinéma du Festival de Cannes ${ }^{48}$.

S'il ne parle pas directement à tous les A fricains - il est évidemment qu'un cinéaste n'arrive jamais à parler à tout un continent -, il parle fortement aux artisans du cinéma africain. II est la voix incontournable, le passage obligé à contester ou à suivre, comme en fait foi leurs témoignages dans Référence Sembène (2002), un documentaire de Yacouba Traoré sur le tournage de M oolaadé, ou encore les films d'un Bekolo ou M oussa Sene A bsa qui, à divers niveaux, notamment par le questionnement de leur rapport aux cinémas occidentaux et africains (problème plus que cher à Sembène O usmane tant dans sa vie que dans ses films) font manifestement écho à sa poéthique. $\mathrm{N}$ 'est-ce pas le comble du succès d'être à la fois cinéaste de cinéastes (africains), et cinéaste des habitants d'un village des plus reculés du pays profond africain ?

48. Voir Les Leçons de cinéma (de Beaque 2007), avec entre autres des textes de Youssef C hahine, M ilosForman, Stephen Frears, N anni M oretti, Sydney Pollack, Francesco Rosi, Volker Schlondörff, Oliver Stone, Bertrand Tavernier, A gnès Varda, W im W enders, W ong Kar Wai. 


\section{Bio-biliographie \& Filmographie annotées de Sembène Ousmane (1923-2007)}

[N otez les changements de fréquences et de formes de production avant et après les indépendances africaines (1960); avant et après les premiers longs métrages (1966) ]

1956, Le Docker noir [roman]. Paris, Debresse.

1957, 0 Pays, mon beau peuple! [roman]. Paris, Le Livre contemporain/ A miot Dumont.

1960, Les Bouts de bois de D ieu : Banty M am Yall [roman]. Paris, Le Livre contemporain/ A miot Dumont.

1960. Indépendances africaines.

1961. Sembène O usmane quitte la France où il vivait depuis la fin de

la Deuxième Guerre mondiale, et retourne en A frique.

1962. Études cinématographiques au Studio Gorki à Moscou.

Pour rejoindre son peuple; passage de l'écrit à l'écran, du roman à la nouvelle, recours au wolof ou au français africain comme langue des titres.

1962, V oltaïque [nouvelles]. Paris, Présence africaine (dernières éditions, après le film, La N oire de... : Voltaïque/ La N oire de ... ).

1963. Sembène O usmane réalise ses premiers films, deux courts métrages: L'Empire Songhaï et Borom Sarret (premier film africain présenté à un festival international, Prix de la première œuvre au Festival de Tours).

1964. Il sort son premier moyen métrage : $N$ iaye.

1964, L'H armattan. Livre I: Référendum [roman]. Paris, Présence africaine, 299 p. (Partie d'un plus large projet jamais terminé, un seul volume publié)

1965, Véhi-C iosane ou Blanche G enèse suivi du M andat [nouvelles]. Paris, Présence africaine. (dernières éditions, après le film, $M$ andabi: Le $M$ andat, précédé de $V$ éhi-C iosane).

1966. Premier long métrage réalisé par Sembène O usmane, mais diffusé comme moyen métrage, La N oire de... [Prix Jean-Vigo, Tamit d'or, C arthage], et son premier grand succès cinématographique. Le film a été présenté dans divers festivals de films dont le prestigieux Festival de $\mathrm{C}$ annes. Depuis, il est de plus en plus impliqué dans la production cinématographique: $M$ andabi (1968) [Prix spécial du jury Venise] ; Taaw (1970) ; E mitaï (1971) ; X ala (1974) ; C eddo (1976) ; Camp de Thiaroye (1988 - co-réalisateur Thierno Faty Sow) ; G uelwaar (1992) ; Faat-K ine (2000) ; M oolaadé (2004). 
1968. M andabi, un premier film en wolof (qui existe aussi en version originale titrée, Le M andat).

Pour mieux rejoindre son peuple: passage du français au wolof ou d'autres langues africaines, dans les titres notamment des films, mais aussi des livres avec deux exceptions notoires Le $M$ andat (terme inexistant en wolof), et $L e$ Dernier de l'E mpire (fort probablement un vieux projet). Par ailleurs, en mettant entre parenthèses $N$ iaye (1964), version filmique de V éhi-C iosane (1965), il faut souligner un certain renversement dans le rapport É crit/ Écran ; désormais des films sont produits avant la publication de leurs livres éponymes Taaw (1970) ; G uelwaar (1993).

1973. Xala [roman]. Paris, Présence africaine.

1981. Le Dernier de I'E mpire (roman sénégalais). Paris, L'H armattan, 2 vol.

1987. N iiwam, suivi de Taaw [nouvelles]. Paris, L'H armattan.

1996. G uelwaar [roman]. Paris, Présence africaine.

Plusieurs livres et films tant en anglais qu'en français sont entièrement consacrés à l'œuvre de Sembène 0 usmane. Parmi eux on peut souligner :

\section{a) Livres}

Vieyra, Paulin Soumanou, 1972, 0 usmane Sembène cinéaste : première période, 1962-1971, Paris, Présence africaine [autre titre: Sembène 0 usmane cinéaste].

Pfaff, Françoise, 1984, The C inema of 0 usmane Sembène. Wesport, Greewood Press.

Gadjigo, Samba et al., 1993, 0 usmane Sembène. D ialogues with C ritics and W riters. A mherst, U niversity of M assachusetts Press.

$N$ zabatsinda, A nthère, 1996, N ormes linguistiques et écriture africaine chez 0 usmane Sembène. Toronto, éditions du G ref.

Diagne, Ismaïla, 2004, Les Sociétés africaines au miroir de Sembène 0 usmane. Paris, L'H armattan.

$\mathrm{G}$ adjigo, Samba, 2007, 0 usmane Sembène, une conscience africaine. $G$ enèse d'un destin hors du commun. Paris, Homnisphères.

Bush, A nnett et M ax A nnas (dir.), 2008, 0 usmane Sembène Interviews. Jackson, U niversity Press of $\mathrm{M}$ ississipi.

\section{b) Films}

Référence Sembène de Yacouba Traoré (2002)

The M aking of M oolaadé de Samba Gadjigo (2004) 


\section{Références}

A rmes, Roy, 2008, Dictionnaire des cinéastes africains de long métrage. Paris, Karthala et éditions ATM .

,----- 2008 , Dictionary of A frican Filmmakers. Bloomington,

Indiana U niversity Press.

Bestman, M artin, 1974, « Sembène 0 usmane cinéaste ». É tudes littéraires

7 (3) : 495-497.

Brière, Éloïse, 2007, «Recycler I'histoire de la décolonisation : fiction

et lieux de mémoire ». French Colonial H istory $8:$ 139-154.

Bush, A nnett et M ax A nnas (dir.), 2008, 0 usmane Sembène Interviews. Jackson, U niversity Press of $\mathrm{M}$ ississipi.

Cervoni, A lbert, 1982 [1965], « U ne confrontation historique en 1965 entre Jean Rouch et Sembène O usmane : Tu nous regardes comme des insectes ». CinémA ction $17:$ 77-78.

Coulpier, Guillaume et Victorine Senthiles, 2008 [2005], Bribes d'une conversation avec T hérèse $M$ 'bissine $D$ iop. D ans $C$ inéastes africains vol. 1, DVD 1. Paris. A rte Vidéo.

Diallo, Doudou, 1983, " L'aube tragique du $1^{\text {er }}$ décembre 1944 à Thiaroye (Sénégal) ». A frique histoire $7:$ 49-51.

Diallo, Siradiou, 1973, "Jeune A frique fait parler Sembène O usmane». Jeune A frique 629 : 44-49.

Diouf, M amadou, 1997 [@1996], « H istoires et actualités dans CEDD 0 d'O usmane Sembene et HYENES de Djibril Diop Mambéty. Dans Sada Niang (dir.), Littérature et cinéma en A frique francophone: 0 usmane Sembène et A ssia Djebar. Paris, L'H armattan : 15-34.

Baeque, A ntoine de (dir.), 2007, Les Leçons de cinéma. Paris, Festival de Cannes/ Panama.

Demougin, Jacques (dir.), 1986, Dictionnaire historique, thématique et technique des littératures. Paris, Larousse.

Diouf, M amadou, 1997 [@1996], « H istoires et actualités dans CEDD 0 d'O usmane Sembene et H YEN ES de Djibril Diop M ambéty ». Dans Sada Niang (dir.), Littérature et cinéma en A frique francophone: 0 usmane Sembène et A ssia Djebar. Paris, L'H armattan : 15-34.

G adjigo, Samba et al (dir.), 1993, 0 usmane Sembène: Dialogues with $C$ ritics and W riters. A mherst: U niversity of M assachusetts Press. G adjigo, Samba, 2004, "O usmane Sembene and H istory on the Screen: A Look Back to the Future ». Dans Françoise Pfaff (dir.), Focus on A frican films. Bloomington, Indiana U niversity Press : 33-47.

- - - - , 2007, 0 usmane Sembène une conscience africaine: genèse d'un destin hors du commun. Paris, Homnisphères. 
Ginsburg, Faye, 1996, "Two Kinds of Truth ». A merican A nthropologist 98 (4): 832-836.

- - - - , 2005, «Dans le bain avec Rouch: A Reminiscence ». A merican A nthropologist 107 (1) : 109-111.

$\mathrm{H}$ affner, Pierre, 1985, "Sandy et Bozambo : entretien avec Jean Rouch sur Sembène O usmane ». C inémA ction 34 : 86-94.

H ennebelle, G uy, 1968, "O usmane Sembene » [entretien]. Jeune cinéma $34:$ 4-9.

- - - - , 1985, "Sembène parle de ses films ». C inémA ction 34 :

25-29.

- - - - , 2008 [1975], «Entretien avec Sembène O usmane ». Dans

Cinéastes africains vol. 1. Livret (sous la direction de $C$ atherine Ruelle). Paris, A rte Vidéo : 7-15.

Izard, M ichel, 2007 [1991], «L'enquête ethnographique ». Dans Pierre

Bonte, M ichel Izard et al. (dir.), Dictionnaire de l'ethnologie et de I'anthropologie. Paris, Q uadrige: 470-474.

Jonassaint, Jean, 1978, "L'expérience du groupe UKAMAU : pour un cinéma militant et populaire ». Dérives $13: 41-57$.

Kom, A mbroise (dir.), 1983, Dictionnaire des oeuvres littéraires négroafricaines de langue française. Sherbrooke, N aaman.

Laplantine, François, et Francine Saillant, 2005, « G Iobalisation, terrain

et théorie. L'anthropologie retraversée ». Parcours anthropologiques $5: 21-28$.

Malinowski, Bronislaw, 1922, A rgonauts of the Western Pacific. Londres et $\mathrm{New}$ York, Routledge, E.P. Dutton.

$M$ artineau, M onique, Yvonne M ignot-Lefebvre, Guy $\mathrm{H}$ ennebelle et A ndré Pâquet [Table ronde avec Jean Rouch], 1982, «Conclusion (un peu) polémique. Cinéma ethnographique et cinéma d'intervention sociale. Des frères ennemis ? » C inémA ction 17 : 164175.

M eyer, Charlotte, 2005, Les $\mathrm{N}$ aissances du cinéma francophone subsaharien : les regards croisés de Jean Rouch et 0 usmane Sembène. M émoire de maîtrise. Rimouski, U niversité du Québec à Rimouski. M itterand, H enri (dir.), 1995, Dictionnaire des œuvres du XX ${ }^{\mathrm{e}}$ siècle. Paris, Le Robert.

M oitt, Bernard, 1997, «R ace, résistance et tirailleurs sénégalais. U ne analyse de Camp de Thiaroye d'O usmane Sembène ». Dans Sada $\mathrm{N}$ iang (dir.), Littérature et cinéma en A frique francophone. 0 usmane Sembène et A ssia D jebar. Paris, L'H armattan : 122-138.

M olino, Jean, 1988, «Pour la poïétique». Revue de C ritique et de T héorie littéraire $7: 7-31$. 
O 'R eilly, Karen, 2005, E thnographic M ethods. Londres et N ew York,

R outledge.

O usmane, Sembène : voir Sembène, O usmane.

N ave, Bernard, 1977, «Émitaï ». Jeune cinéma 103 : 34-36.

Petty, Sheila, 1991, "La Représentation des femmes dans le cinéma africain ». Dans M ichel Larouche (dir.), Films d'A frique. M ontréal, Guernica : 127-141.

Rouch, Jean, 1960, La Religion et la magie Songhay. Paris, PU F.

Sembène, O usmane, 1965, Le M andat précédé de Véhi C iosane. Paris, Présence africaine.

- - - - , [entretien avec Jean et G inette Delmas], 1976, « Un film est un débat ». Jeune cinéma $99: 13-17$.

- - - - , 2007, «O usmane Sembène ». Dans Les Leçons de cinéma, édition établie par A ntoine de Baeque. Paris, Festival de Cannes/ Panama.

Solanas, Fernando, 1975, «Le troisième cinéma : I'expérience du groupe «Cine Liberación ». D érives 3/4 : 17-25.

Tine, Alioune, 1985, "Sembène et son rapport à la langue de communication littéraire. La prééminence objective du français et la prééminence subjective du wolof ». A nnales de la faculté des lettres et Sciences H umaines de Dakar 15 : 207-220.

Toliver-Diallo, Wilmetta J., 2005, «T he Woman W ho Was More than a $\mathrm{M}$ an. $\mathrm{M}$ aking $\mathrm{A}$ line Sitoe Diatta into a $\mathrm{N}$ ational $\mathrm{H}$ eroine in Senegal ». C anadian Journal of A frican Studies/ Revue Canadienne des Études A fricaines 39 (2) : 338-360.

Van den Avenne, Cécile, 2008, "Les petits noirs du type y a bon Banania, messieurs, c'est terminé. L'usage subversif du français tirailleur dans C amp de Thiaroye de Sembène O usmane ». G lottopol 18 : 111-122. http://www.univ-rouen.fr/dyalang/glottopol/ numero_12.htm (consulté en août 2009).

Vieyra, Paulin Soumanou, 1972, 0 usmane Sembène cinéaste: première période 1962-1971. Paris, Présence africaine. [A utre titre: Sembène O usmane cinéaste.] 